\title{
Persistence across Pleistocene ice ages in Mediterranean and extra-Mediterranean refugia: phylogeographic insights from the common wall lizard
}

Daniele Salvi", D James Harris, Antigoni Kaliontzopoulou, Miguel A Carretero and Catarina Pinho

\begin{abstract}
Background: Pleistocene climatic oscillations have played a major role in structuring present-day biodiversity. The southern Mediterranean peninsulas have long been recognized as major glacial refugia, from where Northern Europe was post-glacially colonized. However, recent studies have unravelled numerous additional refugia also in northern regions. We investigated the phylogeographic pattern of the widespread Western Palaearctic lizard Podarcis muralis, using a range-wide multilocus approach, to evaluate whether it is concordant with a recent expansion from southern glacial refugia or alternatively from a combination of Mediterranean and northern refugia.

Results: We analyzed DNA sequences of two mitochondrial (cytb and nd4) and three nuclear ( $a c m 4, m c 1$, and pdc) gene fragments in individuals from 52 localities across the species range, using phylogenetic and phylogeographic methods. The complex phylogeographic pattern observed, with 23 reciprocally monophyletic allo- parapatric lineages having a Pleistocene divergence, suggests a scenario of long-term isolation in multiple ice-age refugia across the species distribution range. Multiple lineages were identified within the three Mediterranean peninsulas Iberia, Italy and the Balkans - where the highest genetic diversity was observed. Such an unprecedented phylogeographic pattern - here called "refugia within all refugia" - compasses the classical scenario of multiple southern refugia. However, unlike the southern refugia model, various distinct lineages were also found in northern regions, suggesting that additional refugia in France, Northern Italy, Eastern Alps and Central Balkans allowed the long-term persistence of this species throughout Pleistocene glaciations.

Conclusions: The phylogeography of Podarcis muralis provides a paradigm of temperate species survival in Mediterranean and extra-Mediterranean glacial refugia. Such refugia acted as independent biogeographic compartments for the long-term persistence of this species, for the differentiation of its genetic lineages, and for the short-distance post-glacial re-colonization of neighbouring areas. This finding echoes previous findings from recent phylogeographic studies on species from temperate ecoregions, thus suggesting the need for a reappraisal of the role of northern refugia for glacial persistence and post-glacial assembly of Holarctic biota.
\end{abstract}

Keywords: Podarcis muralis, Phylogeography, Western Palaearctic, Glacial refugia, Mediterranean peninsulas, Genetic diversity, Temperate species

\footnotetext{
* Correspondence: danielesalvi.bio@gmail.com

$\mathrm{CIBIO}$, Centro de Investigação em Biodiversidade e Recursos Genéticos,

Universidade do Porto; Campus Agrário de Vairão, 4485-661, Vairão, Portugal
} 


\section{Background}

Pleistocene climatic oscillations have played a major role in structuring current biodiversity patterns and shaping the distribution of species and their genetic diversity both at the regional and global scale [1,2]. In recent decades, phylogeographic studies have been used to assess the genetic consequences of Pleistocene ice ages on various organisms, highlighting the dynamic nature of species ranges and the role of microevolutionary processes in determining the extent and structure of intraspecific diversity $[1,3,4]$.

In Europe, the genetic structure of temperate organisms has been mainly explained by cycles of contraction toward glacial refugia located in southern peninsulas and postglacial recolonization of northern regions, tracking the expansion of suitable habitats [5,6] Accordingly, southern peninsular refugia are thought to have played a major role in the long-term maintenance of genetic diversity and differentiation, and relatively few patterns and routes of colonization have been described as paradigms for the post-glacial arrival of species in Northern Europe [6-8].

However, in recent years, multiple evidence from paleoclimatic, palaeontological and phylogeographic studies have identified the existence of glacial refugia in northern regions of Europe, or "northern refugia", and have highlighted the prominent contribution of these refugia to the present-day genetic diversity of many organisms [9-12]. Mounting examples from plants, insects, mammals, amphibians, and reptiles show that in many temperate species the southern refugia model is insufficient to explain the observed genetic patterns, which would be better explained by a scenario of ice-age survival in a combination of Mediterranean and extra-Mediterranean refugia [13-17]. This changing view with respect to geographical location of refugia has also had direct implications for the inferred scenarios of recolonization for many widespread species from the Western Palaearctic. This is true even in emblematic species, such as the brown bear and the common beech, the phylogeographic patterns of which were previously upheld as paradigms of postglacial recolonization routes (exclusively) from southern refugia [6,7]. In these species, the existence of additional extra-Mediterranean refugia has recently become evident through the analysis of fossil DNA and palaeobotanical data, respectively. These evidence suggests that range shifts and expansions in these species could have been much smaller than previously thought [18-21].

Detailed phylogeographic data from widespread Western Palaearctic species are particularly valuable for evaluating the plausibility of a scenario of ice-age survival in Mediterranean and extra-Mediterranean refugia. The common Wall lizard, Podarcis muralis (Laurenti, 1768) is a Western Palaearctic species which provides a suitable case-study for this purpose. Podarcis muralis is a locally abundant lacertid lizard found in a variety of environments across a wide altitudinal range (from sea level to over $2000 \mathrm{~m}$ of altitude). It exhibits considerable variation in colour patterns, biometry and pholidosis, which has led to the description of several subspecies $[22,23]$. The distribution of $P$. muralis is unusual relative to that of its congeners and, together with other characteristics, makes this species a useful model for evaluating the relative contribution of southern versus extra-Mediterranean refugia in shaping the current distribution of species and their genetic diversity. Firstly, it covers a wide range across the Western Palaearcticfrom North-Eastern Anatolia and the Black Sea coast through all the Mediterranean peninsulas - Iberia, Italy, the Balkans- as well as across extra-Mediterranean regions of France, Germany, Slovenia, Austria and the Central Balkans (Figure 1). Secondly, it is abundant in both Mediterranean and continental climatic conditions and its distribution does not seem to be strongly limited by the presence of other lizards. Throughout the southern peninsulas $P$. muralis occurs in sympatry with more localized Podarcis species, such as members of the $P$. hispanica group in the Iberian Peninsula, $P$. sicula in the Italian Peninsula, and $P$. erhardii in the Balkans as well as with members of the genera Lacerta, Iberolacerta, and Timon across its whole range. Also, it is a highly successful invasive species in North-Western Europe where around 150 non-native $P$. muralis populations have been identified [24]. Thus, Mediterranean and extra-Mediterranean areas seem generally suitable for the survival and colonization of this species. Moreover, although little is presently known about the evolutionary history of $P$. muralis, either a scenario of recent colonization of its northern range from a southern primary range or a long-term history of the species in some of these northern areas can be invoked to explain the observed intraspecific variation. Harris and Arnold [25] hypothesized that P. muralis recently colonized most of its distribution from the Italian Peninsula, based on the observation that it exhibits the greatest morphological and allozyme diversity in Italy [26]. On the other hand, recent genetic assessment identified divergent genetic lineages - likely of Pleistocene origin - in Italy but also in France and the Balkans, disproving a colonization of these two latter areas from Italy [24,27,28]. Nevertheless, these studies have been limited to small parts of the range and analyzed only mitochondrial DNA, and particularly partial cytochrome $b$ sequences, thus preventing a full appreciation of the origin of these lineages and of the overall evolutionary history and biogeography of the species.

In this study, we analysed DNA sequences data from 86 individuals from 52 localities across the species range, including extensive sampling in the Mediterranean peninsulas where native diversity is expected to be highest. 

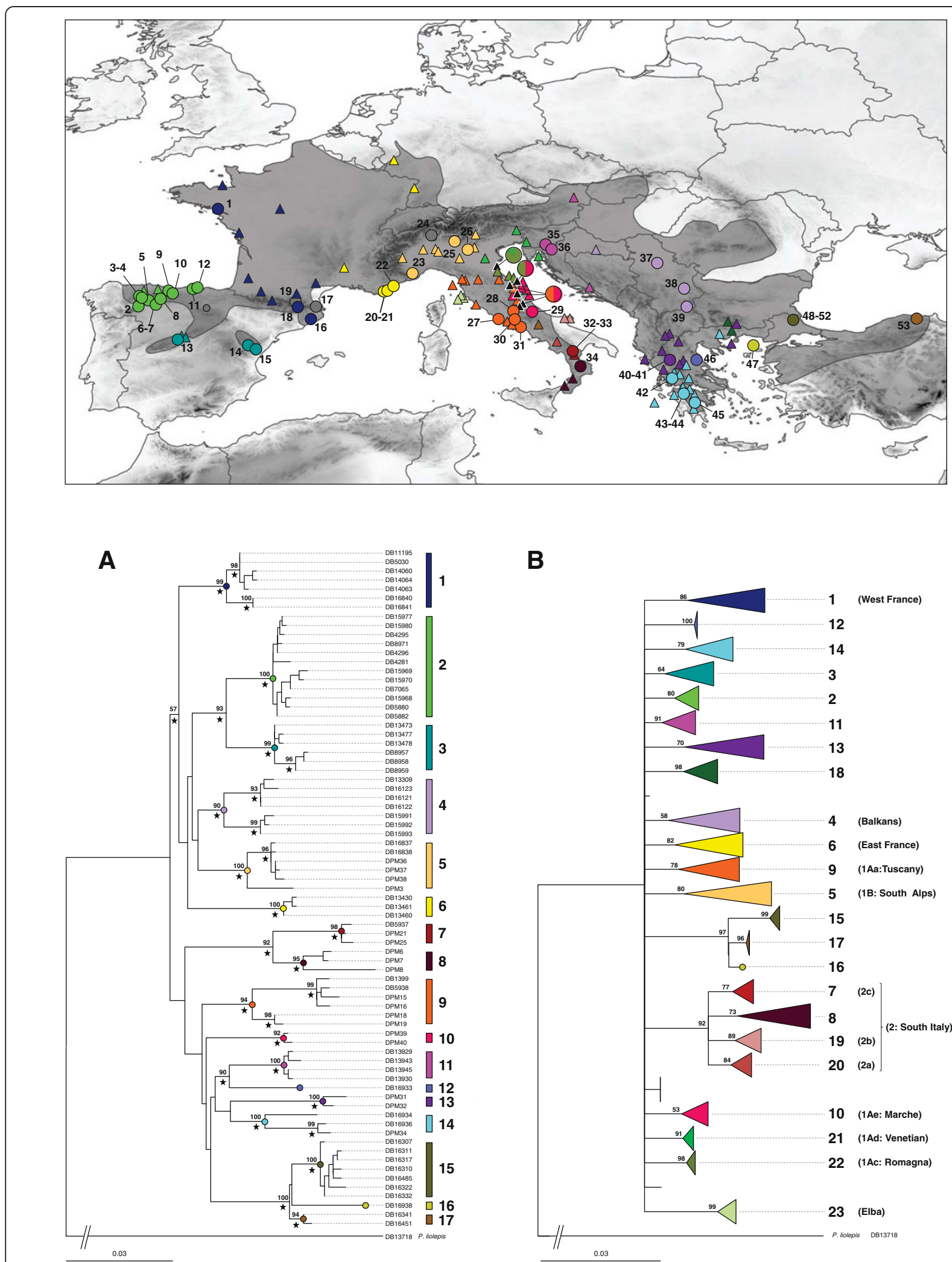

B

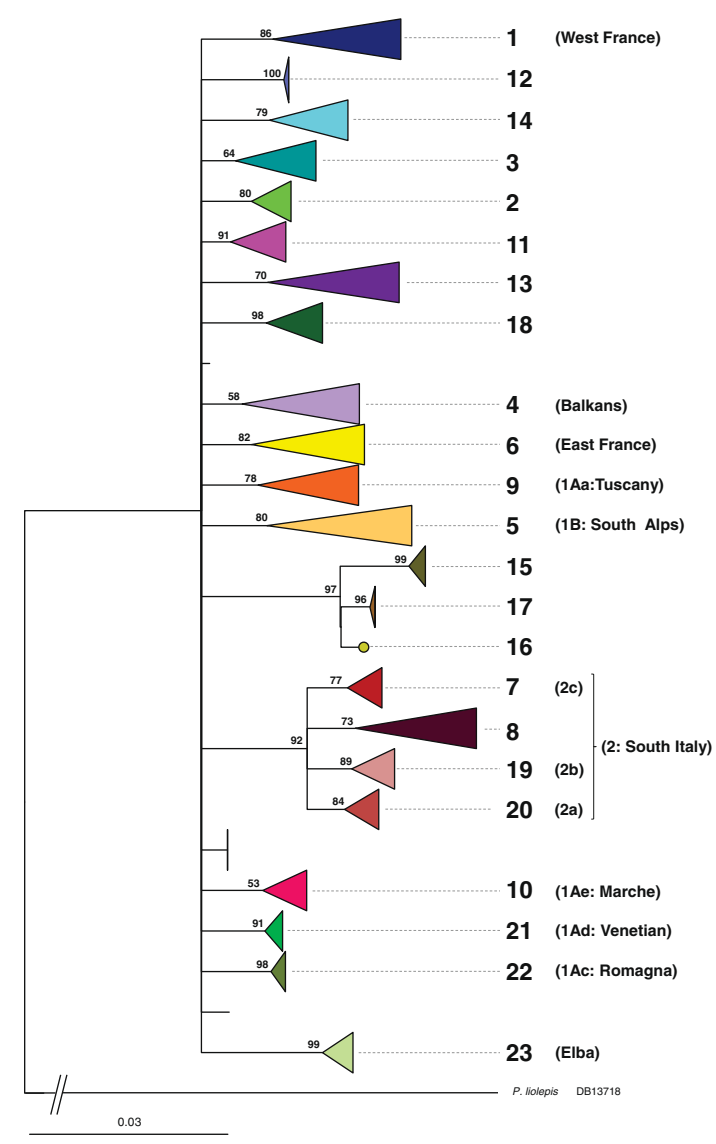

Figure 1 (See legend on next page.) 
(See figure on previous page.)

Figure 1 Sampling localities, phylogenetic relationships, and distribution of mitochondrial haplotypes and haploclades. Maximum Likelihood (ML) trees depicting the phylogenetic relationships among 75 combined mitochondrial sequences (cytb and nd4) of Podarcis muralis from 52 localities (A) and among 185 cytb sequences of Podarcis muralis obtained in this study ( $N=82$ ) and from GenBank, ( $N=103)$ (see Additional file 1) (B). ML bootstrap values over 1000 replicates are reported in correspondence to the nodes; black stars indicate BA posterior probabilities $=1.00$; Podarcis liolepis was used as an outgroup. In the combined cytb/nd4 ML tree specimen codes are reported (see Table 1 for details) and main mitochondrial clades numbered from 1 to 17; in the cytb ML tree tip nodes are collapsed and main mitochondrial clades are numbered from 1 to 23 according to the combined cytb/nd4 ML tree and named according to previous studies. Samples used in this study and geographic distribution of mitochondrial clades are reported in the map: big circles show the 53 localities sampled in this study and triangles show the geographic origin for the cytb sequences obtained from GenBank, coloured according to mitochondrial clades defined by the ML trees (black triangles indicate admixed populations for which the frequency of haplotypes belonging to each clades is shown by the pie diagrams; grey circles indicate samples for which only nuclear sequences were available).

We used two partial mitochondrial genes (cytb and $n d 4)$, and three partial nuclear genes $(a c m 4, m c 1 r$, and $p d c)$, all of which have been successfully used for assessing variation within other species of lacertids (e.g. $[29,30]$ ). Furthermore, by comparing 103 published cytochrome $b$ sequences from previous studies with our assessment, we placed these in a more robust phylogenetic framework, and further used them to confirm that all known diversity was included in this study. This comprehensive data set enables us to evaluate whether the patterns of genetic variation observed in this species reflect a recent expansion from a single or a few Pleistocene southern glacial refugia or, alternatively, from a combination of Mediterranean and extra-Mediterranean refugia. Under the first scenario we expect to identify endemic lineages in one or more southern refugia, to observe only southernderived haplotypes in northern areas, and an overall pattern of 'southern richness $v s$ northern purity' of genetic diversity $[1,2,6]$. Alternatively, if $P$. muralis also survived in northern glacial refugia, we predict an occurrence of lineages endemic to northern regions, with an ancient (Pleistocene) divergence from southern lineages, and an absence of a northern purity pattern of genetic diversity. The main goal of our range-wide multilocus approach is, therefore, to identify the biogeographic and evolutionary processes shaping the genetic diversity of $P$. muralis and to discuss, in the framework of European phylogeography, how this species came to have such an unusual biogeographic pattern.

\section{Methods}

\section{Data collection}

We sampled a total of 86 individuals from 52 localities spanning the range of Podarcis muralis with particular attention to the Iberian, Italian, and Balkan peninsulas. Three specimens of two Iberian Podarcis, P. liolepis (Boulenger, 1905) and P. bocagei (Seoane, 1884), and the Italian wall lizard P. sicula (Rafinesque-Schmaltz, 1810), were sampled and designated as outgroups. We used multiple outgroups because the phylogenetic position of P. muralis within the genus Podarcis is not well resolved, yet this species seems more closely related to Iberian
Podarcis or P. sicula [31,32]. Additionally, partial cytb sequences for 103 individuals were obtained from GenBank and included in phylogenetic analyses. Specimens included in molecular analyses, together with collection locality details, are reported in Table 1 and Figure 1. Accession numbers for sequences retrieved from GenBank are reported in Additional file 1.

Total genomic DNA was extracted from alcoholpreserved tail muscle collected from live specimens following standard high-salt protocols [33]. Portions of five genes were amplified by polymerase chain reaction: two mitochondrial genes, cytochrome $b(c y t b)$ and NADH dehydrogenase subunit 4 with flanking tRNAs ( $n d 4)$, and three nuclear genes, Melanocortin receptor 1 ( $m c 1 r)$, acetylcholinergic receptor M4 (acm4), and Phosducin $(p d c)$. The primers used for amplification and respective references are reported in Additional file 2. For $p d c$ we used primers newly developed for this study. Amplifications were carried out in $25 \mu \mathrm{L}$ volumes, containing 1X PCR buffer $(50 \mathrm{~mm}$ Tris- $\mathrm{HCl}, 50 \mathrm{~mm} \mathrm{NaCl}$, pH 8.5); $3 \mathrm{mM} \mathrm{MgCl} 2 ; 0.6 \mathrm{mM}$ each dNTP, 2U of GoTaq DNA polymerase (Promega), $0.4 \mu \mathrm{M}$ each primer and approximately $50 \mathrm{ng}$ of genomic DNA. Amplification conditions consisted of a preliminary denaturation step at $92^{\circ} \mathrm{C}$ for 3 minutes, followed by 16 touchdown cycles with 30 seconds at $92^{\circ} \mathrm{C}$, annealing temperature decreasing $0.5^{\circ} \mathrm{C}$ per cycle from $60^{\circ} \mathrm{C}$ to $52^{\circ} \mathrm{C}$ (30 seconds) and extension for 1 minute at $72^{\circ} \mathrm{C}$. 20 more cycles similar to these but with annealing temperatures stable at $52^{\circ} \mathrm{C}$ followed. A final extension was carried out at $72^{\circ} \mathrm{C}$ for 15 minutes.

\section{Data analysis}

Electropherograms were checked and consensus sequences were aligned in GENEIOUS 6.0 (www.geneious.com) using the Geneious Alignment algorithm. We discarded the hypothesis of pseudogenes occurring in our mitochondrial sequence dataset by confirming: (i) the absence of stop codons in protein-coding fragments, (ii) the consistency of the base composition pattern with a mitochondrial origin (less than $5 \%$ of guanines in the third position, see [34]), and (iii) the overall similarity with the reference mitochondrial genome of $P$. muralis (Genbank accession number 
Table 1 Geographical location and codes for the studied specimens of Podarcis muralis and the outgroup species $P$. liolepis

\begin{tabular}{|c|c|c|c|c|c|c|c|c|c|}
\hline \multirow{3}{*}{$\begin{array}{l}\begin{array}{l}\text { Specimen } \\
\text { code }\end{array} \\
\mathrm{DB} 16840\end{array}$} & \multirow{3}{*}{$\begin{array}{c}\text { Locality } \\
\text { code }\end{array}$} & \multirow{3}{*}{$\begin{array}{c}\text { Locality } \\
\text { he (France) }\end{array}$} & & & \multicolumn{5}{|c|}{ Genbank accession numbers } \\
\hline & & & \multicolumn{2}{|c|}{ Coordinates } & \multirow{2}{*}{$\begin{array}{c}\text { cytb } \\
\text { KF372191 }\end{array}$} & \multirow{2}{*}{$\begin{array}{c}\text { nd4 } \\
\text { KF372350 }\end{array}$} & \multirow{2}{*}{$\frac{\boldsymbol{m c 1 r}}{\mathrm{KF} 372113}$} & \multirow{2}{*}{$\begin{array}{c}\text { acm4 } \\
\text { KF372273 }\end{array}$} & \multirow{2}{*}{$\begin{array}{c}\text { pdc } \\
\text { KF372036 }\end{array}$} \\
\hline & & & $47.50 \mathrm{~N}$ & $-2.38 \mathrm{E}$ & & & & & \\
\hline DB16841 & 1 & Vieille-Roche (France) & $47.50 \mathrm{~N}$ & $-2.38 \mathrm{E}$ & KF372192 & KF372351 & KF372114 & KF372274 & KF372037 \\
\hline DB4296 & 2 & Palacios de Compludo (Spain) & $42.46 \mathrm{~N}$ & $-6.47 \mathrm{E}$ & KF372193 & KF372352 & KF372115 & KF372275 & KF372038 \\
\hline DB15980 & 3 & Braña de Sosas (Spain) & $43.00 \mathrm{~N}$ & $-6.31 E$ & KF372194 & KF372353 & KF372116 & KF372276 & KF372039 \\
\hline DB15977 & 4 & Señora de Carrasconte (Spain) & $42.94 \mathrm{~N}$ & $-6.23 E$ & KF372195 & KF372354 & KF372117 & KF372277 & KF372040 \\
\hline DB4281 & 5 & La Omañuela (Spain) & $42.78 \mathrm{~N}$ & $-5.98 \mathrm{E}$ & KF372196 & KF372355 & KF372118 & - & - \\
\hline DB4295 & 6 & León (Spain) & $42.59 \mathrm{~N}$ & $-5.58 \mathrm{E}$ & KF372197 & KF372356 & KF372119 & KF372278 & KF372041 \\
\hline DB15968 & 7 & La Candamia (Spain) & $42.60 \mathrm{~N}$ & $-5.55 E$ & KF372198 & KF372357 & KF372120 & KF372279 & KF372042 \\
\hline DB15969 & 8 & Valdehuesa (Spain) & $42.94 \mathrm{~N}$ & $-5.32 \mathrm{E}$ & KF372199 & KF372358 & KF372121 & KF372280 & KF372043 \\
\hline DB15970 & 8 & Valdehuesa (Spain) & $42.94 \mathrm{~N}$ & $-5.32 \mathrm{E}$ & KF372200 & KF372359 & KF372122 & KF372281 & KF372044 \\
\hline DB8970 & 9 & Tanes (Spain) & $43.21 \mathrm{~N}$ & $-5.40 \mathrm{E}$ & KF372201 & - & KF372123 & KF372282 & KF372045 \\
\hline DB8971 & 9 & Tanes (Spain) & $43.21 \mathrm{~N}$ & $-5.40 \mathrm{E}$ & KF372202 & KF372360 & KF372124 & KF372283 & KF372046 \\
\hline DB7092 & 10 & Turieno (Spain) & $43.16 \mathrm{~N}$ & $-4.66 \mathrm{E}$ & - & KF372361 & KF372125 & KF372284 & KF372047 \\
\hline DB5880 & 11 & Matienzo (Spain) & $43.33 \mathrm{~N}$ & $-3.59 \mathrm{E}$ & KF372203 & KF372362 & KF372126 & KF372285 & KF372048 \\
\hline DB5882 & 11 & Matienzo (Spain) & $43.33 \mathrm{~N}$ & $-3.59 \mathrm{E}$ & KF372204 & KF372363 & KF372127 & KF372286 & KF372049 \\
\hline DB7065 & 12 & Oriñon (Spain) & $43.40 \mathrm{~N}$ & $-3.33 E$ & KF372205 & KF372364 & KF372128 & KF372287 & KF372050 \\
\hline DB8957 & 13 & Guadarrama (Spain) & $40.71 \mathrm{~N}$ & $-4.14 \mathrm{E}$ & KF372206 & KF372365 & KF372129 & KF372288 & KF372051 \\
\hline DB8958 & 13 & Guadarrama (Spain) & $40.71 \mathrm{~N}$ & $-4.14 \mathrm{E}$ & KF372207 & KF372366 & KF372130 & KF372289 & KF372052 \\
\hline DB8959 & 13 & Guadarrama (Spain) & $40.71 \mathrm{~N}$ & $-4.14 \mathrm{E}$ & KF372208 & KF372367 & - & - & - \\
\hline DB13472 & 14 & Gúdar (Spain) & $40.37 \mathrm{~N}$ & $-0.67 \mathrm{E}$ & - & - & KF372131 & - & KF372053 \\
\hline DB13473 & 14 & Gúdar (Spain) & $40.37 \mathrm{~N}$ & $-0.67 \mathrm{E}$ & KF372209 & KF372368 & KF372132 & KF372290 & KF372054 \\
\hline DB13477 & 15 & Penyagolosa (Spain) & $40.23 \mathrm{~N}$ & $-0.35 E$ & KF372210 & KF372369 & KF372133 & KF372291 & KF372055 \\
\hline DB13478 & 15 & Penyagolosa (Spain) & $40.23 \mathrm{~N}$ & $-0.35 E$ & KF372211 & KF372370 & KF372134 & KF372292 & KF372056 \\
\hline DB14060 & 16 & Montseny (Spain) & $41.77 \mathrm{~N}$ & $2.44 \mathrm{E}$ & KF372212 & KF372371 & KF372135 & KF372293 & KF372057 \\
\hline DB14063 & 16 & Montseny (Spain) & $41.77 \mathrm{~N}$ & $2.44 \mathrm{E}$ & KF372213 & KF372372 & KF372136 & KF372294 & KF372058 \\
\hline DB14064 & 16 & Montseny (Spain) & $41.77 \mathrm{~N}$ & $2.44 \mathrm{E}$ & KF372214 & KF372373 & KF372137 & KF372295 & KF372059 \\
\hline DB1759 & 17 & Les Salines (Spain) & $42.42 \mathrm{~N}$ & $2.75 E$ & KF372215 & - & - & - & - \\
\hline DB5030 & 18 & Meranges (Spain) & $42.43 \mathrm{~N}$ & $1.78 \mathrm{E}$ & KF372216 & KF372374 & KF372138 & KF372296 & KF372060 \\
\hline DB11195 & 18 & Meranges (Spain) & $42.43 \mathrm{~N}$ & $1.78 \mathrm{E}$ & KF372217 & KF372375 & KF372139 & KF372297 & - \\
\hline DB13718* & 19 & Luzenac (France) & $42.75 \mathrm{~N}$ & $1.75 \mathrm{E}$ & KF372218 & KF372376 & - & - & - \\
\hline DB13461 & 20 & Massif des Maures (France) & $43.24 \mathrm{~N}$ & $6.38 \mathrm{E}$ & KF372219 & KF372377 & KF372140 & KF372298 & KF372061 \\
\hline DB13460 & 21 & Valle de Gilly (France) & $43.28 \mathrm{~N}$ & $6.46 \mathrm{E}$ & KF372220 & KF372378 & KF372141 & KF372299 & KF372062 \\
\hline DB13430 & 22 & Massif des Maures (France) & $43.38 \mathrm{~N}$ & $6.62 \mathrm{E}$ & KF372221 & KF372379 & KF372142 & KF372300 & KF372063 \\
\hline DPM1 & 23 & Viozene (Italy) & $44.14 \mathrm{~N}$ & $7.78 \mathrm{E}$ & KF372222 & - & KF372143 & KF372301 & KF372064 \\
\hline DPM3 & 23 & Viozene (Italy) & $44.14 \mathrm{~N}$ & $7.78 \mathrm{E}$ & KF372223 & KF372380 & KF372144 & KF372302 & KF372065 \\
\hline DB15936 & 24 & Monte Verita (Switzerland) & $46.16 \mathrm{~N}$ & $8.72 \mathrm{E}$ & KF372224 & - & - & - & - \\
\hline DB16837 & 25 & Bianzano (Italy) & $45.77 \mathrm{~N}$ & $9.92 \mathrm{E}$ & KF372225 & KF372381 & KF372145 & KF372303 & KF372066 \\
\hline DB16838 & 25 & Bianzano (Italy) & $45.77 \mathrm{~N}$ & $9.92 \mathrm{E}$ & KF372226 & KF372382 & KF372146 & KF372304 & - \\
\hline DPM36 & 26 & Peschiera del Garda (Italy) & $45.44 \mathrm{~N}$ & $10.67 \mathrm{E}$ & KF372227 & KF372383 & KF372147 & KF372305 & KF372067 \\
\hline DPM37 & 26 & Peschiera del Garda (Italy) & $45.44 \mathrm{~N}$ & $10.67 \mathrm{E}$ & KF372228 & KF372384 & - & KF372306 & KF372068 \\
\hline DPM38 & 26 & Peschiera del Garda (Italy) & $45.44 \mathrm{~N}$ & $10.67 \mathrm{E}$ & KF372229 & KF372385 & KF372148 & KF372307 & KF372069 \\
\hline
\end{tabular}


Table 1 Geographical location and codes for the studied specimens of Podarcis muralis and the outgroup species P. liolepis (Continued)

\begin{tabular}{|c|c|c|c|c|c|c|c|c|c|}
\hline DB1399 & 27 & Ostia Antica (Italy) & $41.75 \mathrm{~N}$ & $12.31 \mathrm{E}$ & KF372230 & KF372386 & KF372149 & KF372308 & KF372070 \\
\hline DB5938 & 28 & Paganico (Italy) & $42.19 \mathrm{~N}$ & $13.00 \mathrm{E}$ & KF372231 & KF372387 & KF372150 & KF372309 & KF372071 \\
\hline DPM39 & 29 & Majelletta (Italy) & $42.16 \mathrm{~N}$ & $14.13 \mathrm{E}$ & KF372232 & KF372388 & KF372151 & KF372310 & KF372072 \\
\hline DPM40 & 29 & Majelletta (Italy) & $42.16 \mathrm{~N}$ & $14.13 \mathrm{E}$ & KF372233 & KF372389 & KF372152 & KF372311 & KF372073 \\
\hline DPM41 & 29 & Majelletta (Italy) & $42.16 \mathrm{~N}$ & $14.13 \mathrm{E}$ & KF372234 & - & - & - & KF372074 \\
\hline DPM15 & 30 & Bassiano (Italy) & $41.55 \mathrm{~N}$ & $13.05 \mathrm{E}$ & KF372235 & KF372390 & KF372153 & KF372312 & KF372075 \\
\hline DPM16 & 30 & Bassiano (Italy) & $41.55 \mathrm{~N}$ & $13.05 \mathrm{E}$ & KF372236 & KF372391 & KF372154 & KF372313 & KF372076 \\
\hline DPM18 & 31 & Fondi (Italy) & $41.37 \mathrm{~N}$ & $13.33 \mathrm{E}$ & KF372237 & KF372392 & KF372155 & KF372314 & KF372077 \\
\hline DPM19 & 31 & Fondi (Italy) & $41.37 \mathrm{~N}$ & $13.33 \mathrm{E}$ & KF372238 & KF372393 & KF372156 & KF372315 & KF372078 \\
\hline DPM25 & 32 & Pollino National Park (Italy) & $39.93 N$ & $16.17 \mathrm{E}$ & KF372239 & KF372394 & KF372157 & KF372316 & KF372079 \\
\hline DB5937 & 33 & Pollino National Park (Italy) & $39.90 \mathrm{~N}$ & $16.19 \mathrm{E}$ & KF372240 & KF372395 & KF372158 & KF372317 & KF372080 \\
\hline DPM21 & 33 & Pollino National Park (Italy) & $39.90 \mathrm{~N}$ & $16.19 \mathrm{E}$ & KF372241 & KF372396 & KF372159 & KF372318 & KF372081 \\
\hline DPM7 & 34 & Fago del Soldato (Italy) & $39.35 \mathrm{~N}$ & $16.55 \mathrm{E}$ & KF372242 & KF372397 & KF372160 & KF372319 & KF372082 \\
\hline DPM8 & 34 & Fago del Soldato (Italy) & $39.35 \mathrm{~N}$ & $16.55 \mathrm{E}$ & KF372243 & KF372398 & KF372161 & KF372320 & KF372083 \\
\hline DPM6 & 34 & Fago del Soldato (Italy) & $39.35 \mathrm{~N}$ & $16.55 \mathrm{E}$ & KF372244 & KF372399 & KF372162 & KF372321 & KF372084 \\
\hline DB13929 & 35 & Ribnica (Slovenia) & $45.75 \mathrm{~N}$ & $14.77 \mathrm{E}$ & KF372245 & KF372400 & KF372163 & KF372322 & KF372085 \\
\hline DB13930 & 35 & Ribnica (Slovenia) & $45.75 \mathrm{~N}$ & $14.77 \mathrm{E}$ & KF372246 & KF372401 & KF372164 & KF372323 & KF372086 \\
\hline DB13943 & 36 & Donja Lamana Draga (Slovenia) & $45.51 \mathrm{~N}$ & $14.96 \mathrm{E}$ & KF372247 & KF372402 & KF372165 & KF372324 & KF372087 \\
\hline DB13945 & 36 & Donja Lamana Draga (Slovenia) & $45.51 \mathrm{~N}$ & $14.96 \mathrm{E}$ & KF372248 & KF372403 & KF372166 & KF372325 & KF372088 \\
\hline DB15991 & 37 & Zuce (Serbia) & $44.68 \mathrm{~N}$ & $20.55 \mathrm{E}$ & KF372249 & KF372404 & KF372167 & KF372326 & KF372089 \\
\hline DB15992 & 37 & Zuce (Serbia) & $44.68 \mathrm{~N}$ & $20.55 \mathrm{E}$ & KF372250 & KF372405 & KF372168 & KF372327 & KF372090 \\
\hline DB15993 & 37 & Zuce (Serbia) & $44.68 \mathrm{~N}$ & $20.55 \mathrm{E}$ & KF372251 & KF372406 & KF372169 & KF372328 & KF372091 \\
\hline DB13309 & 38 & Сиheво (Serbia) & N & $22.08 \mathrm{E}$ & $\mathrm{KF} 3$ & 407 & KF37 & KF372 & KF372092 \\
\hline DB16121 & 39 & Road to Crnovska River (Serbia) & $42.38 \mathrm{~N}$ & $22.05 \mathrm{E}$ & KF372253 & KF372408 & KF372171 & KF372330 & KF372093 \\
\hline DB16122 & 39 & Road to Crnovska River (Serbia) & $42.38 \mathrm{~N}$ & $22.05 \mathrm{E}$ & KF372254 & KF372409 & KF372172 & KF372331 & KF372094 \\
\hline DB16123 & 39 & Road to Crnovska River (Serbia) & $42.38 \mathrm{~N}$ & $22.05 \mathrm{E}$ & KF372255 & KF372410 & KF372173 & KF372332 & KF372095 \\
\hline DPM31 & 40 & Metsovo (Greeece) & $39.71 \mathrm{~N}$ & $21.19 \mathrm{E}$ & KF372256 & KF372411 & KF372174 & KF372333 & KF372096 \\
\hline DPM32 & 41 & Metsovo (Greeece) & $39.71 \mathrm{~N}$ & $21.21 \mathrm{E}$ & KF372257 & KF372412 & KF372175 & KF372334 & KF372097 \\
\hline DB16934 & 42 & Velouxi (Greece) & $38.85 \mathrm{~N}$ & $21.38 \mathrm{E}$ & KF372258 & KF372413 & - & KF372335 & KF372098 \\
\hline DPM34 & 43 & Platanitsa, Achaia (Greece) & $37.97 \mathrm{~N}$ & $21.88 \mathrm{E}$ & KF372259 & KF372414 & KF372176 & KF372336 & KF372099 \\
\hline DPM35 & 44 & Platanitsa, Achaia (Greece) & $37.96 \mathrm{~N}$ & $21.91 \mathrm{E}$ & KF372260 & - & KF372177 & KF372337 & KF372100 \\
\hline DB16936 & 45 & Mainalo, Pelloponnisos (Greece) & $37.39 \mathrm{~N}$ & $22.46 \mathrm{E}$ & KF372261 & KF372415 & - & - & - \\
\hline DB16933 & 46 & Kisavos mt (Greece) & $39.63 N$ & $22.64 \mathrm{E}$ & KF372262 & KF372416 & - & - & - \\
\hline DB16938 & 47 & Samothraki isl. (Greece) & $40.45 \mathrm{~N}$ & $25.59 \mathrm{E}$ & KF372263 & KF372417 & KF372178 & KF372338 & - \\
\hline DB16310 & 48 & Kapakli (Turkey) & $41.89 \mathrm{~N}$ & $27.35 \mathrm{E}$ & KF372264 & KF372418 & KF372179 & KF372339 & KF372101 \\
\hline DB16307 & 49 & Kapakli (Turkey) & $41.91 \mathrm{~N}$ & $27.36 \mathrm{E}$ & KF372265 & KF372419 & KF372180 & KF372340 & KF372102 \\
\hline DB16311 & 50 & Dereköy (Turkey) & $41.96 \mathrm{~N}$ & $27.39 \mathrm{E}$ & KF372266 & KF372420 & KF372181 & KF372341 & KF372103 \\
\hline DB16317 & 50 & Dereköy (Turkey) & $41.96 \mathrm{~N}$ & $27.39 \mathrm{E}$ & KF372267 & KF372421 & KF372182 & KF372342 & KF372104 \\
\hline DB16482 & 50 & Dereköy (Turkey) & $41.96 \mathrm{~N}$ & $27.39 \mathrm{E}$ & - & KF372422 & KF372183 & KF372343 & KF372105 \\
\hline DB16322 & 51 & Dereköy (Turkey) & $41.97 \mathrm{~N}$ & $27.42 \mathrm{E}$ & KF372268 & KF372423 & KF372184 & KF372344 & KF372106 \\
\hline DB16332 & 51 & Dereköy (Turkey) & $41.97 \mathrm{~N}$ & $27.42 \mathrm{E}$ & KF372269 & KF372424 & KF372185 & KF372345 & KF372107 \\
\hline DB16485 & 51 & Dereköy (Turkey) & $41.97 \mathrm{~N}$ & $27.42 \mathrm{E}$ & KF372270 & KF372425 & KF372186 & KF372346 & KF372108 \\
\hline DB16318 & 52 & Dereköy (Turkey) & $41.96 \mathrm{~N}$ & $27.45 \mathrm{E}$ & - & KF372426 & KF372187 & KF372347 & KF372109 \\
\hline
\end{tabular}


Table 1 Geographical location and codes for the studied specimens of Podarcis muralis and the outgroup species P. liolepis (Continued)

\begin{tabular}{|c|c|c|c|c|c|c|c|c|c|}
\hline DB16341 & 53 & Pınarözü (Turkey) & $41.77 \mathrm{~N}$ & $34.04 \mathrm{E}$ & KF372271 & KF372427 & KF372188 & KF372348 & KF372110 \\
\hline DB16340 & 53 & Pınarözü (Turkey) & $41.77 \mathrm{~N}$ & $34.04 \mathrm{E}$ & - & KF372428 & KF372189 & KF372349 & KF372111 \\
\hline DB16451 & 53 & Pınarözü (Turkey) & $41.77 \mathrm{~N}$ & $34.04 \mathrm{E}$ & KF372272 & KF372429 & KF372190 & - & KF372112 \\
\hline
\end{tabular}

Specimen and code locality along with geographic coordinates are reported. Genbank Accession Numbers for each gene are provided. * ${ }^{*}$ tgroup species: P. liolepis.

FJ460597). Haplotype phase of nuclear genes was determined using PHASE version 2.1.1. [35]. Estimations were carried out under a model with recombination (-MR0 option), with the initial 1000 iterations discarded as burn-in, 1 as thinning interval and 1000 post-burnin iterations. Three independent runs were conducted for each gene. After monitoring the goodness of fit for each run according to the program's manual, we accepted haplotype reconstructions which both i) yielded the same result in each of the three runs, and ii) had associated phase posterior probabilities of at least 0.75 in the average of the three runs. For each nuclear gene, the possible occurrence of recombination events was assessed using the Pairwise Homoplasy Index (PHI) test [36] implemented in SPLITSTREE 4.11 [37].

In order to assess patterns of genetic diversity and evaluate whether southern peninsulas harboured most of the diversity of $P$. muralis, we estimated the overall genetic diversity of the species and its distribution across populations and regions. For each gene we computed the following summary statistics of genetic diversity: number of segregating sites $S$, nucleotide diversity $\pi$, number of haplotypes $H$, and haplotype diversity $H d$, both overall and for specific groups or clades defined within the species (see Results and Discussion) with DNASP 5 [38]. Comparisons of diversity measures can be greatly affected by different sample sizes among groups. In order to account for this, we followed a resampling approach: given the lowest sample size (except 0 or 1 ) amongst the various groups being compared (s), for each group with sample size $>$ s we resampled 100 sets of s sequences, calculated diversity measures for each of these 100 sets and took the average for each diversity measure. This procedure allows a straightforward comparison of diversity measures derived from groups or clades with distinct sample sizes. Resampling was performed with the aid of a series of scripts written in Python 2.7.1 (available from the authors upon request) and taking advantage of DNASP "batch mode" calculations. Average uncorrected genetic distances between mitochondrial clades were assessed using MEGA 5 [39]. Furtehrmore, to assess genetic differentiation between clades we calculated $F_{\mathrm{ST}}$ (based on $p$-distance) and its significance by performing 1000 permutations in ARLEQUIN 3.5.1.2 [40].

Phylogenetic relationships among mitochondrial haplotypes were inferred using Maximum Likelihood (ML) and Bayesian (BA) methods. We tested three outgroups, P. liolepis, P. bocagei, and P. sicula (both combined and separately) through preliminary ML and BA tree searches. The outgroup effect on the ML and BA topologies was limited and differences between trees calculated using different outgroups were limited to unsupported nodes (not shown). Thus, we present and discuss phylogenetic analyses using $P$. liolepis as an outgroup (Genbank Accession numbers for P. bocagei cytb/nd4: DQ081139/DQ081153; for P. sicula cytb/nd4: KF372034/KF372035; for P. liolepis see Table 1). The ML search and the model selection were carried out in TREEFINDER version October 2008 [41]. We selected the best partitioned model of nucleotide substitution under the corrected Akaike's Information Criterion (AICc) by comparing the AICc scores of seven different partition schemes (under a fixed ML topology): (i) by gene fragments (cytb/nd4+tRNAs), (ii) by genes (cytb/ $n d 4 /$ tRNAs); (iii) by coding regions ( $c y t b+n d 4 /$ tRNAs), (iv-v) by codon position alone (two schemes:1st/2nd/3rd and $1 s t+2 n d / 3 r d$ ), and (vi-vii) by codon position, in combination with gene partitions (for a total of seven or five partitions, depending on the codon partitioning scheme). The optimal model had seven partitions, three codon partitions for each coding gene and one partition for tRNAs (cytb: HKY for the 1st, the 2nd, and the 3rd codon positions; $n d 4: \mathrm{TN}+\mathrm{G}$ for the the 1st, and $\mathrm{HKY}+\mathrm{G}$ for the 2nd and the 3rd codon positions; tRNAs: $\mathrm{HKY}+\mathrm{G}$, each model with frequency and rate heterogeneity parameters optimisation). We performed a global tree search using 100 random start trees generated through equidistant random walks of random nearest-neighbour-interchanges (NNI) starting from the centre tree obtained by a simple ML search. Support for the nodes (BP) was evaluated with 1000 bootstrap replicates. Additionally, in order to evaluate the total mitochondrial variation known for this species, we carried out a ML analysis following the same procedure as above (the best model in this case was the HKY with a single partition), using a dataset including both the cytb sequences generated in this study $(\mathrm{N}=82)$ and those available in GenBank for native populations of P. muralis $(\mathrm{N}=103)$. This dataset provides even greater coverage of the whole species range (see Figure 1). The obtained phylogenetic trees were visualised and edited using FigTree v.1.3.1 (available at http://tree.bio.ed.ac. $\mathrm{uk} /$ software/figtree/). The geographic pattern of haplogroup distribution and the relationships between 
haplotypes help to disentangle the two alternative scenarios predicted by the southern refugia model or by a model of Mediterranean and extra-Mediterranean refugia. For this purpose, we mapped the distribution of haplogroups identified by the phylogenetic trees across our range-wide sampling.

Bayesian analyses were carried out using the BEAST v.1.7.4 package [42] for two purposes: i) to estimate a phylogeny of the combined mitochondrial DNA dataset based on Bayesian inference; ii) to obtain estimates of the mtDNA time to the most recent common ancestor (TMRCA) of P. muralis and groups detected within the species. The choice of an appropriate tree prior for this dataset is somewhat problematic: on one hand, the bulk of our data is intraspecific, hence a "speciation" prior such as the Yule process may not be adequate. On the other hand, because the presence of an outgroup is mandatory and due to the high levels of geographic substructure detected in our focal species (see Results), our data are not totally amenable to analyses under a basic coalescent process. Therefore, we performed these analyses under both a Yule process and a coalescent process with constant size, to evaluate the effect of prior selection on our estimates of phylogeny and TMRCAs. To avoid overparametrization, we implemented a model with a simpler partition scheme, defined by gene fragments (two-partitions), and selected under AICc in TREEFINDER. The best evolutionary model for our dataset assumed the $\mathrm{HKY}+\mathrm{G}$ and the TIM2+G+I substitution models for the cytb and $n d 4$ fragments, respectively. The TIM2 model was manually specified within the BEAUti input file [42]. To infer mtDNA TMRCAs, we assumed a relaxed molecular clock for both cytb and $n d 4$, applying an uncorrelated lognormal model [43]. We used the available rates proposed for Podarcis for the longer fragment, $n d 4$, while providing a large uninformative prior for the $c y t b$ substitution rate (parameter ucld.mean). In the case of $n d 4$ we assumed that differences accumulate at a mean rate of $2.26 \%$ per million years, obtained as the average between divergence rates proposed for Podarcis for this fragment (ranging from $1.74 \%$ to $2.78 \%$ per million years; [44]). In order to incorporate this uncertainty into TMRCA estimates, we defined a normal prior distribution on the mutation rate with mean $1.13 \% / \mathrm{MY}$ and with $95 \%$ of the probability distribution encompassed between the two aforementioned limits ( 0.87 and $1.39 \%$, respectively). For each tree prior, BEAST was run twice, with 100 million iterations per run, sampling every 10000 steps. TRACER v. 1.5 (available at http://beast.bio.ed.ac.uk/Tracer) was used to visualize the results and assess if the effective sample size of estimated parameters was satisfactory. We discarded the initial $10 \%$ of sampled trees as burn-in. Upon confirmation of convergence, the two outputs for each tree prior were combined and subsequent data were retrieved from the combined data set.
For the following analyses, we considered as clades groups of haplotypes which are reciprocally monophyletic at the mitochondrial loci with the ML and BA tree reconstructions; displaying geographical contiguity; and divergent by more than $1 \%$ with its closer relative in line with previous studies $([24,27,28]$; see also [45]). While we acknowledge that such criteria could be considered arbitrary, to further test that these groups correspond to evolutionary significant lineages, ESU sensu [46], we confirmed they show significant divergence of allele frequencies at nuclear loci as assessed by $F_{\mathrm{ST}}$ statistics (see above).

To assess how genetic variance at the combined cytb/ $n d 4$ sequences was hierarchically distributed among and within mitochondrial clades, we performed a spatial analysis of molecular variance (SAMOVA) with SAMOVA 1.0 [47]. We pooled samples from neighbouring localities in accordance with the mitochondrial clades previously identified. Geographic coordinates for each clade were calculated as the geographic centroid of member localities. Clades represented by less than two individuals were not included in the analysis. SAMOVA was run for 10,000 iterations from each of 100 random initial conditions, and testing the predefined number of groups $(K)$ from 2 to 14 .

Phylogenetic relationships among nuclear haplotypes were inferred by median joining networks [48] using the software NETWORK 4.6.1.0 (available at http://www. fluxus-engineering.com/sharenet.htm).

Finally, we specifically tested the hypothesis of a recent expansion of $P$. muralis from southern glacial refugia against the alternative scenario of Pleistocene survival of the species in both southern and northern refugia. The first hypothesis implies that northern localities belong to the same genetic pool as the southern region from which they originated. As such, sequence divergence between northern and southern localities will be, in most cases, significantly lower than the divergence observed between clades and possibly similar to intraclade divergence. By contrast, the latter hypothesis implies that northern regions have hosted surviving populations which have evolved independently from southern ones. Thus, we expect the mean sequence divergence between northern and southern localities to be similar to mean divergence among clades. This rationale provides a statistical framework to explicitly compare the two competing hypotheses. A requisite of this test is that mean between-clade sequence divergence is significantly higher than withinclade divergence. Therefore, as a first step, we performed a permutation test to evaluate if between-clade $p$-distances $\left(D_{b c}\right)$ were significantly higher than within-clade distances $\left(D_{w c}\right)$. For this purpose, we randomly shuffled individuals among clades 1000 times in order to obtain the empirical distribution of the difference $D_{b c}-D_{w c}$. The corresponding $p$-value was then obtained as the 
percentage of times for which the observed $D_{b c}-D_{w c}$ was smaller than random. This test was performed for the combined mitochondrial DNA data set, as well as for the three nuclear loci in separate, always using the units defined on the basis of the mtDNA phylogeny. In continuation, for each northern locality and for each locus, we evaluated if the sequence divergence from southern localities fell within the "between-clade" or the "within-clade" level of differentiation. We classified localities as "northern" or "southern" according to biogeographic barriers separating central Europe from major glacial refugia in southern peninsulas as defined by previous literature $[1,4,5,7,15]$ : localities north or east to the Pyrenees (locality 1), north to the Appennine chain (localities 25-26), west or east to the Alps (localities 20-23 and 35-36, respectively), and in the central Balkans (localities 37-39) were therefore considered as "northern". For each northern locality we performed two different tests: first, we examined its mean $p$-distance from all southern localities (localities 2-16, 18, 27-34, and 4046). Second, to account for the possibility that northern localities may have been preferably colonized from adjacent refugia, we also examined the mean $p$-distance of each northern locality from contiguous southern regions only (locality 1 vs localities $2-16$, and 18; localities 20 26 vs localities $27-34$; localities $37-39$ vs. localities $40-$ 46; localities 35-36 were compared either with localities 27-34 or with localities 40-46, given their intermediate geographic location). These comparisons were performed according to the following permutation procedure: individuals were shuffled among localities at random across 1000 permutation cycles. In each permutation, we calculated the mean $p$-distance between each northern locality and the set of southern localities being compared $\left(D_{i}\right.$, where $i$ is the code of the northern locality), the mean between-clade distance $\left(D_{b c}\right)$ and the mean within-clade distance $\left(D_{w c}\right)$. For each northern locality $i$, we then assessed whether the difference between $D_{b c}$ and $D_{i}\left(D_{b c}-\right.$ $D_{i}$ ) was equal or higher than the distance we observed in the real data. The same was done for the difference between $D_{i}$ and $D_{w c}\left(D_{i}-D_{w c}\right)$. The proportion of permutations verifying each of these conditions was used as a $p$-value to assess if the observed differences were significant or could be due to chance alone.

\section{Results}

We obtained 82 cytb mitochondrial sequences of 411 base pairs (bp), $79 n d 4$ mitochondrial sequences of 873 bp (75 individuals sequenced for both fragments), 156 sequences for the nuclear gene fragment $m c 1 r$, and 154 for $a c m 4$ and $p d c$ with 688bp, $423 \mathrm{bp}$, and $342 \mathrm{bp}$, respectively. GenBank accession numbers for the sequences generated in this study are reported in Table 1. Multiple sequence alignment did not require gap positions in any of the studied genes. The phi test did not find statistically significant evidence for recombination within nuclear gene fragments $(p>0.05)$. Sample size and localities, and clade assignment are reported in Table 2.

The phylogenetic relationships inferred from the ML tree based on the combined mitochondrial sequences showed 17 well supported clades $(B P \geq 90)$ with a geographic coherence (Figure 1A). The Bayesian tree showed an identical topology at supported nodes (not shown) with the same 17 clades supported with a posterior probability of 1.00 (Figure 1A), independently of the choice of tree prior. Clade 1 grouped haplotypes from Northwest France and Southeast Pyrenees (Spain). Haplotypes included in clades 2 and 3 occurred in populations from Northern and Central Spain, respectively. Clade 6 is restricted to Provence, France. Five different clades occurred in Italy: clade 5 in Northern Italy beneath the Alpine arch; clades 9 and 10 in central Italy; and clades 7 and 8 in the Calabrian Peninsula. Slovenian populations clustered in clade 11 and samples from Serbia in clade 4. In the Balkan Peninsula, clades 12,13, and 14 were distributed in Thessaly, Central Greece, and Peloponnese regions, respectively. Clade 16 is restricted to Samothraki Island and clades 15 and 17 are distributed in Turkish Thrace and North-Western Anatolia, respectively. Clades 12 and 16 were formed by single haplotypes, and as such they cannot be strictly considered as clades. However, we use the term 'clade' for simplicity, given their divergence from other clades, and, in the case of clade 12, also because this is indeed formed by multiple haplotypes in the analyses including Genbank sequences (see below and Figure 1B). The average uncorrected genetic distance between mitochondrial clades was 4.5 and $3.1 \%$ for $c y t b$ and $n d 4$ respectively (ranging from 1 to $7.4 \%$ for $c y t b$ and 0.9 to $4.7 \%$ for $n d 4$ ) and both loci show significant $F_{\mathrm{ST}}$ values $(0.86$ and 0.83 for $c y t b$ and $n d 4$ respectively; $P=0.001)$. Clades 15,16 , and 17 showed the lowest pairwise distance values at both cytb (1\%) and $n d 4$ (0.9\%), while the minimum value of pairwise genetic distances across other clades was $1.8 \%$ for both genes. Phylogenetic relationships between Iberian clades West of the Pyrenees (clades 2 and 3), between southern Italian clades (clades 7 and 8), between Slovenian and Balkan clades (clades 11 and 12), and among clades from Turkey and Samothraki (clades 15-17) were well supported in both ML and BA trees, while the relationships between clades 1-6 was supported in BA but not in $\mathrm{ML}$ analyses $(\mathrm{BP}<60)$. The relationships between the remaining clades were not resolved.

The ML analysis combining the 84 cytb sequences generated in this study and 103 sequences published from previous studies showed 23 well supported clades (Figure 1B). These included the 17 clades identified based on the combined cytb/nd4 ML tree and are numbered according to the combined ML tree (Figure 1A) and named according to previous studies [22,26,27]. 


\begin{tabular}{|c|c|c|c|c|c|c|c|c|c|c|c|c|c|c|c|c|c|c|c|c|c|c|c|c|c|c|c|c|c|c|c|}
\hline \multirow[b]{2}{*}{ Clades } & \multirow[b]{2}{*}{ Localities } & \multicolumn{6}{|c|}{$n d 4$} & \multicolumn{6}{|c|}{ cytb } & \multicolumn{6}{|c|}{$m c 1 r$} & \multicolumn{6}{|c|}{$\mathrm{acm} 4$} & \multicolumn{6}{|c|}{$p d c$} \\
\hline & & $\mathrm{N}$ & ns & $s$ & $h$ & $H d$ & $\begin{array}{c}\pi \\
\left(* 10^{3}\right)\end{array}$ & $\mathrm{N}$ & ns & $S$ & $h$ & $H d$ & $\begin{array}{c}\pi \\
\left({ }^{*} 10^{3}\right)\end{array}$ & $\mathrm{N}$ & ns & $S$ & $h$ & $H d$ & $\begin{array}{c}\pi \\
\left(* 10^{3}\right)\end{array}$ & $\mathbf{N}$ & ns & $S$ & $h$ & $H d$ & $\begin{array}{c}\pi \\
\left({ }^{*} 10^{3}\right)\end{array}$ & $N$ & ns & $S$ & $h$ & $H d$ & $\begin{array}{c}\pi \\
\left(* 10^{3}\right)\end{array}$ \\
\hline \multirow[t]{2}{*}{1} & $1,16,18$ & 7 & 873 & 8 & 5 & 0.91 & 4.67 & 8 & 411 & 5 & 3 & 0.61 & 5.20 & 14 & 683 & 3 & 3 & 0.28 & 0.74 & 14 & 423 & 1 & 2 & 0.26 & 0.82 & 12 & 342 & 2 & 2 & 0.30 & 2.45 \\
\hline & & & 754 & 3.55 & 1.93 & 0.93 & 4.71 & & 391 & 2.07 & 1.63 & 0.63 & 5.48 & & 576 & 0.41 & 1.25 & 0.25 & 0.71 & & 323 & 0.3 & 1.3 & 0.30 & 0.93 & & 248 & 1.24 & 1.62 & 0.33 & 2.69 \\
\hline \multirow[t]{2}{*}{2} & $\begin{array}{l}3-9,11 \\
12\end{array}$ & 13 & 873 & 9 & 13 & 1.00 & 3.98 & 13 & 411 & 2 & 3 & 0.30 & 1.15 & 28 & 683 & 4 & 3 & 0.14 & 0.50 & 26 & 423 & 0 & 1 & 0.00 & 0.00 & 26 & 342 & 3 & 3 & 0.66 & 5.49 \\
\hline & & & 754 & 3.05 & 2 & 1.00 & 4.05 & & 391 & 0.47 & 1.33 & 0.33 & 1.24 & & 576 & 0.54 & 1.24 & 0.24 & 0.94 & & 323 & 0 & 1 & 0.00 & 0.00 & & 248 & 2.41 & 2.41 & 0.68 & 5.56 \\
\hline \multirow[t]{2}{*}{3} & 13- 15 & 6 & 873 & 5 & 5 & 0.93 & 3.36 & 6 & 411 & 4 & 4 & 0.87 & 5.47 & 12 & 683 & 1 & 2 & 0.17 & 0.29 & 10 & 423 & 1 & 2 & 0.20 & 0.62 & 12 & 342 & 2 & 2 & 0.49 & 3.93 \\
\hline & & & 754 & 2.41 & 1.92 & 0.92 & 3.20 & & 391 & 2.09 & 1.9 & 0.90 & 5.53 & & 576 & 0.15 & 1.15 & 0.15 & 0.26 & & 323 & 0.2 & 1.2 & 0.20 & 0.62 & & 248 & 1.66 & 1.83 & 0.47 & 3.82 \\
\hline \multirow[t]{2}{*}{4} & $37-39$ & 7 & 873 & 7 & 6 & 0.95 & 4.93 & 7 & 411 & 7 & 4 & 0.81 & 9.07 & 14 & 683 & 3 & 3 & 0.39 & 1.16 & 14 & 423 & 2 & 3 & 0.56 & 2.35 & 14 & 342 & 4 & 3 & 0.48 & 6.41 \\
\hline & & & 754 & 3.49 & 1.92 & 0.92 & 4.63 & & 391 & 2.94 & 1.75 & 0.75 & 7.78 & & 576 & 0.7 & 1.42 & 0.42 & 1.22 & & 323 & 0.81 & 1.6 & 0.60 & 2.51 & & 248 & 2.72 & 1.94 & 0.45 & 6.01 \\
\hline \multirow[t]{2}{*}{5} & $23,25,26$ & 6 & 873 & 10 & 6 & 1 & 5.31 & 8 & 411 & 8 & 3 & 0.61 & 10.14 & 12 & 683 & 4 & 4 & 0.64 & 1.71 & 14 & 423 & 3 & 4 & 0.75 & 3.61 & 12 & 342 & 3 & 4 & 0.77 & 4.77 \\
\hline & & & 754 & 3.81 & 2 & 1 & 5.05 & & 391 & 3.70 & 1.53 & 0.53 & 9.46 & & 576 & 0.96 & 1.61 & 0.61 & 1.67 & & 323 & 1.29 & 1.77 & 0.77 & 3.99 & & 248 & 2.18 & 2.79 & 0.77 & 4.89 \\
\hline \multirow[t]{2}{*}{6} & $20-22$ & 3 & 873 & 1 & 2 & 0.67 & 0.88 & 3 & 411 & 2 & 3 & 1.00 & 3.53 & 6 & 683 & 0 & 1 & 0.00 & 0.00 & 6 & 423 & 1 & 2 & 0.60 & 1.86 & 6 & 342 & 0 & 1 & 0.00 & 0.00 \\
\hline & & & 754 & 0.65 & 1.65 & 0.65 & 0.86 & & 391 & 1.3 & 2 & 1.00 & 3.44 & & 576 & 0 & 1 & 0.00 & 0.00 & & 323 & 0.51 & 1.51 & 0.51 & 1.58 & & 248 & 0 & 1 & 0.00 & 0.00 \\
\hline \multirow[t]{2}{*}{7} & 32,33 & 3 & 873 & 3 & 3 & 1.00 & 3.10 & 3 & 411 & 1 & 2 & 0.67 & 1.76 & 6 & 683 & 1 & 2 & 0.33 & 0.58 & 6 & 423 & 3 & 5 & 0.93 & 4.33 & 6 & 342 & 3 & 3 & 0.60 & 4.05 \\
\hline & & & 754 & 2.29 & 2 & 1.00 & 3.04 & & 391 & 0.62 & 1.62 & 0.62 & 1.64 & & 576 & 0.29 & 1.29 & 0.29 & 0.50 & & 323 & 1.44 & 1.97 & 0.97 & 4.46 & & 248 & 1.92 & 2.29 & 0.58 & 3.89 \\
\hline \multirow[t]{2}{*}{8} & 34 & 3 & 873 & 11 & 3 & 1.00 & 9.73 & 3 & 411 & 10 & 2 & 0.67 & 17.64 & 6 & 683 & 1 & 2 & 0.33 & 0.58 & 6 & 423 & 2 & 3 & 0.80 & 3.30 & 6 & 342 & 1 & 2 & 0.33 & 1.35 \\
\hline & & & 754 & 7.54 & 2 & 1.00 & 10.00 & & 391 & 7.5 & 1.75 & 0.75 & 19.84 & & 576 & 0.29 & 1.29 & 0.29 & 0.50 & & 323 & 1.05 & 1.78 & 0.78 & 3.25 & & 248 & 0.62 & 1.62 & 0.31 & 1.25 \\
\hline \multirow[t]{2}{*}{9} & $27,28,30,31$ & 6 & 873 & 18 & 6 & 1.00 & 10.52 & 6 & 411 & 9 & 3 & 0.73 & 12.17 & 12 & 683 & 4 & 5 & 0.58 & 1.16 & 12 & 423 & 1 & 2 & 0.17 & 0.52 & 12 & 342 & 2 & 3 & 0.67 & 3.44 \\
\hline & & & 754 & 8.3 & 2 & 1.00 & 11.01 & & 391 & 4.94 & 1.78 & 0.78 & 13.07 & & 576 & 0.63 & 1.54 & 0.54 & 1.09 & & 323 & 0.21 & 1.21 & 0.21 & 0.65 & & 248 & 1.45 & 2.33 & 0.62 & 3.25 \\
\hline \multirow[t]{2}{*}{10} & 29 & 2 & 873 & 2 & 2 & 1.00 & 2.65 & 3 & 411 & 1 & 2 & 0.67 & 1.76 & 4 & 683 & 2 & 2 & 0.50 & 1.74 & 4 & 423 & 1 & 2 & 0.50 & 1.55 & 6 & 342 & 1 & 2 & 0.53 & 2.16 \\
\hline & & & 754 & - & - & - & - & & 391 & 0.67 & 1.67 & 0.67 & 1.77 & & 576 & 1 & 1.5 & 0.50 & 1.74 & & 323 & 0.49 & 1.49 & 0.49 & 1.52 & & 248 & 0.91 & 1.91 & 0.52 & 2.11 \\
\hline 11 & 35,36 & 4 & 873 & 6 & 4 & 1.00 & 4.42 & 4 & 411 & 1 & 2 & 0.50 & 1.32 & 8 & 683 & 2 & 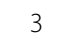 & 0.71 & 1.49 & 8 & 423 & 0 & 1 & 0.00 & 0.00 & 8 & 342 & 1 & 2 & 0.43 & 1.74 \\
\hline & & & 754 & 3.28 & 2 & 1.00 & 4.35 & & 391 & 0.52 & 1.52 & 0.52 & 1.38 & & 576 & 0.85 & 1.71 & 0.71 & 1.48 & & 323 & 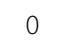 & 1 & 0.00 & 0.00 & & 248 & 0.76 & 1.76 & 0.41 & 1.67 \\
\hline 12 & 46 & 1 & 873 & - & - & - & - & 1 & 411 & - & - & - & - & 0 & - & - & - & - & - & 0 & - & - & - & - & - & 0 & - & - & - & - & - \\
\hline & & & 754 & & & & & & 391 & - & - & - & - & & - & - & - & - & - & & - & - & - & - & - & & - & - & - & - & - \\
\hline 13 & 40,41 & 2 & 873 & 3 & 2 & 1.00 & 3.98 & 2 & 411 & 2 & 2 & 1.00 & 5.29 & 4 & 683 & 1 & 2 & 0.50 & 0.87 & 4 & 423 & 2 & 3 & 0.83 & 3.10 & 4 & 342 & 0 & 1 & 0.00 & 0.00 \\
\hline & & & 754 & - & - & - & - & & 391 & - & - & - & - & & 576 & 0.52 & 1.52 & 0.52 & 0.90 & & 323 & 1.05 & 1.88 & 0.88 & 3.25 & & 248 & - & - & - & - \\
\hline 14 & $42-45$ & 3 & 873 & 16 & 3 & 1.00 & 14.15 & 4 & 411 & 10 & 4 & 1.00 & 14.11 & 4 & 683 & 1 & 2 & 0.50 & 0.87 & 6 & 423 & 0 & 1 & 0.00 & 0.00 & 6 & 342 & 0 & 1 & 0.00 & 0.00 \\
\hline & & & 754 & 10.17 & 2 & 1.00 & 13.49 & & 391 & 5.26 & 2 & 1.00 & 13.92 & & 576 & 0.51 & 1.51 & 0.51 & 0.89 & & 323 & 0 & 1 & 0.00 & 0.00 & & 248 & 0 & 1 & 0.00 & 0.00 \\
\hline 15 & $48-52$ & 9 & 873 & 11 & 9 & 1.00 & 4.86 & 7 & 411 & 0 & 1 & 0.00 & 0.00 & 18 & 683 & 0 & 1 & 0.00 & 0.00 & 18 & 423 & 2 & 3 & 0.45 & 2.45 & 18 & 342 & 0 & 1 & 0.00 & 0.00 \\
\hline & & & 754 & 3.85 & 2 & 1.00 & 5.11 & & 391 & 0 & 1 & 0.00 & 0.00 & & 576 & 0 & 1 & 0.00 & 0.00 & & 323 & 0.8 & 1.45 & 0.45 & 2.48 & & 248 & 0 & 1 & 0.00 & 0.00 \\
\hline
\end{tabular}


Table 2 Summary statistics of genetic diversity for each gene, clade, and region (Continued)

\begin{tabular}{|c|c|c|c|c|c|c|c|c|c|c|c|c|c|c|c|c|c|c|c|c|c|c|c|c|c|c|c|c|c|c|c|}
\hline \multirow[t]{2}{*}{16} & 47 & 1 & 873 & - & - & - & - & 1 & 411 & - & - & - & - & 2 & 683 & 0 & 1 & 0.00 & 0.00 & 2 & 423 & 0 & 1 & 0.00 & 0.00 & 0 & - & - & - & - & - \\
\hline & & & 754 & & & & & & 391 & - & - & - & - & & 576 & - & - & - & - & & 323 & - & - & - & - & & - & - & - & - & - \\
\hline \multirow[t]{3}{*}{17} & 53 & 3 & 873 & 2 & 3 & 1.00 & 1.77 & 2 & 411 & 0 & 1 & 0.00 & 0.00 & 6 & 683 & 0 & 1 & 0.00 & 0.00 & 4 & 423 & 2 & 2 & 0.67 & 4.13 & 6 & 342 & 0 & 1 & 0.00 & 0.00 \\
\hline & & & 754 & 1.26 & 2 & 1.00 & 1.67 & & 391 & - & - & - & - & & 576 & 0 & 1 & 0.00 & 0.00 & & 323 & 1.34 & 1.67 & 0.67 & 4.15 & & 248 & 0 & 1 & 0.00 & 0.00 \\
\hline & & 79 & 873 & 142 & 74 & 1.00 & 28.21 & 81 & 411 & 83 & 42 & 0.97 & 40.05 & 156 & 688 & 24 & 21 & 0.37 & 0.92 & 154 & 423 & 11 & 13 & 0.57 & 2.40 & 154 & 342 & 13 & 12 & 0.73 & 6.67 \\
\hline Region & Clades & & & & & & & & & & & & & & & & & & & & & & & & & & & & & & \\
\hline \multirow[t]{2}{*}{ Balkans } & $12,13,14$ & 7 & 873 & 53 & 7 & 1 & 27.92 & 8 & 411 & 38 & 8 & 1 & 36.66 & 10 & 683 & 2 & 3 & 0.38 & 0.69 & 12 & 423 & 3 & 4 & 0.56 & 1.97 & 10 & 342 & 0 & 1 & 0 & 0.00 \\
\hline & & & 754 & - & - & - & - & & 391 & - & - & - & - & & 576 & - & - & - & - & & 323 & - & - & - & - & & 248 & - & - & - & - \\
\hline \multirow[t]{2}{*}{ Italy } & $7,8,9,10$ & 14 & 873 & 60 & 14 & 1 & 27.49 & 16 & 411 & 43 & 10 & 0.94 & 35.45 & 28 & 683 & 8 & 8 & 0.44 & 0.99 & 28 & 423 & 3 & 5 & 0.57 & 2.19 & 30 & 342 & 6 & 6 & 0.62 & 3.24 \\
\hline & & & 754 & 47.88 & 7 & 1 & 27.25 & & 391 & 34.87 & 6.48 & 9.42 & 35.35 & & 576 & 2.6 & 3.31 & 0.41 & 0.90 & & 323 & 2.58 & 3.85 & 0.56 & 2.17 & & 248 & 2.76 & 3.47 & 0.62 & 3.20 \\
\hline \multirow[t]{2}{*}{ Iberia } & $1^{*}, 2,3$ & 24 & 873 & 32 & 22 & 0.99 & 15.29 & 25 & 411 & 21 & 9 & 9.78 & 18.94 & 50 & 683 & 8 & 6 & 0.19 & 0.56 & 46 & 423 & 2 & 3 & 0.13 & 0.40 & 46 & 342 & 3 & 3 & 0.58 & 4.56 \\
\hline & & & 754 & 24.84 & 6.89 & 0.99 & 14.75 & & 391 & 17.66 & 4.7 & 0.79 & 19.25 & & 576 & 1.61 & 2.06 & 0.20 & 0.56 & & 323 & 0.77 & 1.77 & 0.14 & 0.45 & & 248 & 2.68 & 2.69 & 0.58 & 4.62 \\
\hline
\end{tabular}

$\mathrm{N}$, sample size (in number of gene copies), ns number of sites, $S$, number of segregating sites, $h$ number of haplotypes, $H d$ haplotype diversity, $\pi$ nucleotide diversity. For the diversity measures $S, h, H d$, and $\pi$ values
calculated under a resampling approach are also reported below values calculated on the original datasets. For the number of sites, for each case the first row represents the size of the alignment while the second row represents the number of sites after discarding Ns or unphased positions; "-" means that no resampling was conducted for that set. *excluding locality 1. 
Previous studies had identified 12 of these mitochondrial mtDNA lineages - eight across Italy ("1Aa", "1Ac", "1 Ad", " $1 A e$ ", "1B", " $2 a$ ", " $2 b$ ", and " $2 c$ "; $[26])$, one from the island of Elba [27], and one from each of Western France, Eastern France, and the Balkans [23]. We separated the clades " $1 \mathrm{~A}$ " and " $1 \mathrm{~B}$ " listed in [26] into their constituent sub-clades, since clade " $1 \mathrm{~A}$ " was not supported by phylogenetic analyses and clade " $1 \mathrm{~B}$ " from southern Italy is composed of distinct units (from Calabria, Apulia and Campania), which are as differentiated as the other clades. In our assessment, ten previously undetected clades were identified (clades 2,3, 8, and 11-17 in Figure 1A). Additionally, a new lineage was identified in East Macedonia (clade 18) that had not been previously described as a group despite being comprised of sequences retrieved from GenBank.

MtDNA TMRCA estimates within $P$. muralis were roughly similar independently of the choice of tree prior in BEAST analyses (Additional file 3). The TMRCA of $P$. muralis was estimated at 2.47-2.67 million years ago, thus coinciding with the Plio-Pleistocene boundary. The TMRCA estimates of the various clades bound the period from Early Pleistocene to Late Pleistocene.

SAMOVA analyses showed a lack of genetic structure above the clade level (Additional file 4). No clade grouping explained the genetic variation observed in $P$. muralis significantly better than other grouping options, as indicated by the uniform increase of $F_{\mathrm{CT}}$ values toward higher values of $K$.

The phylogenetic networks depicting the relationships between $a c m 4, m c 1 r$, and $p d c$ haplotypes are shown in Figure 2. The acm4 and mc1r networks showed a pattern of low divergence and a lack of apparent phylogeographic structure, although both show significant $F_{\mathrm{ST}}$ values $(0.37$ and 0.24 respectively; $P=0.001$ ) between mtDNA-defined clades. In both loci the most common haplotypes were found in most localities (with the exception of localities 47 and 53 for $\mathrm{acm} 4$, while locality 46 is not represented in the dataset of these two genes, see Table 1 and 2) and derived haplotypes divergent by one or two mutational steps had a more restricted distribution. On the other hand, evidence of geographic association of nuclear haplotypes was more prominent for the $p d c$ locus (Figure 2), leading to a higher and also significant $F_{\mathrm{ST}}$ value $\left(F_{\mathrm{ST}}=0.56 ; P=0.001\right)$. The structure of the network showed two most frequent haplotypes, each exhibiting derived variants: the haplogroup placed in the left side of the network was restricted to the Balkans, Turkey, Slovenia, and Provence (France), while the haplogroup on the right side included all the haplotypes from Italy. Haplotypes sampled in the Iberian Peninsula and Eastern France belonged to both haplogroups.

Estimates of genetic diversity $S, \pi, H$, and $H d$ for each gene, clade, and geographic region are given in Table 2.

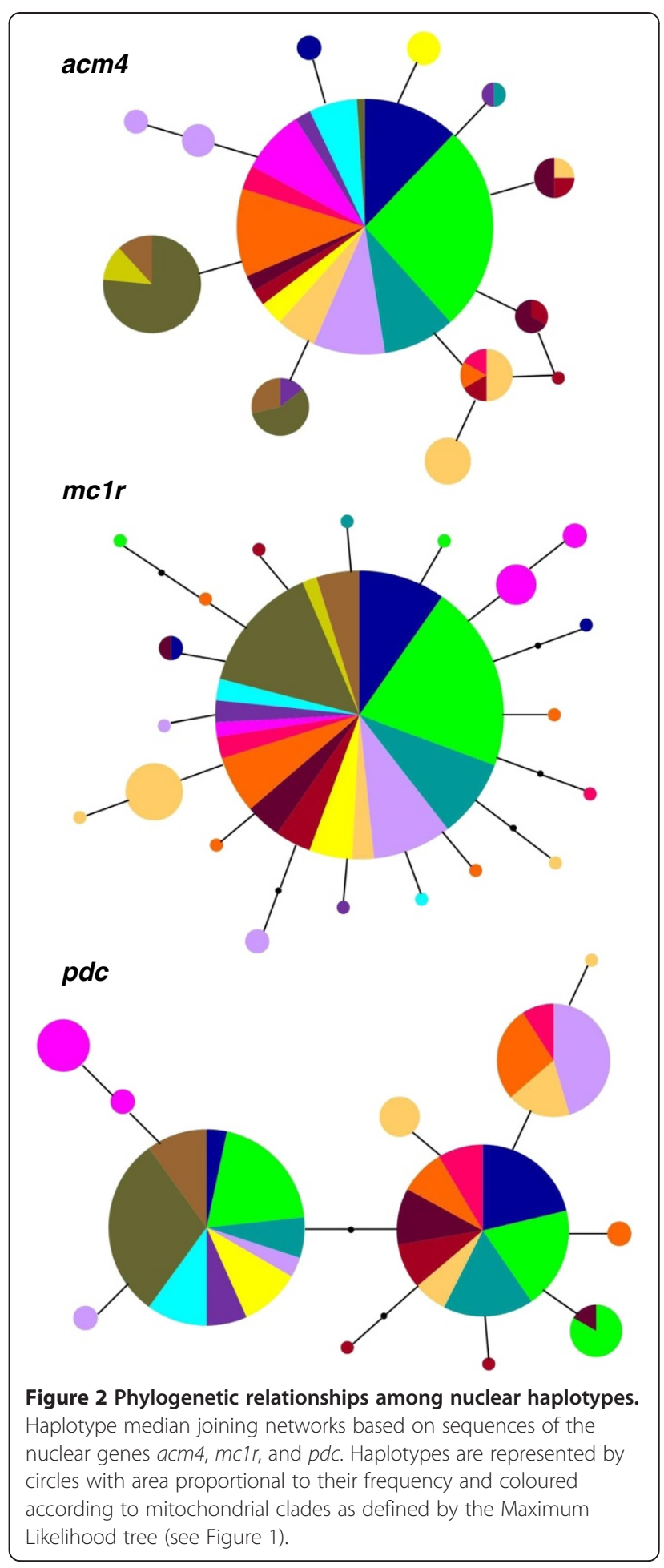

Nucleotide and haplotype diversity of mitochondrial genes was higher in Northern, Central, and Southern Italy (clades 5, 9, and 8, respectively) and in clade 14 from Southern mainland Greece and the Peloponnese. At the nuclear gene level, an overall pattern of low genetic diversity was found. Higher diversity values were 
observed in populations from Northern Italy (clade 5), whereas no clear trend was apparent across putative southern refugial areas.

Permutation tests showed that between-clade $p$-distance is significantly higher than within-clade distances for all loci $\left(D_{b c} / D_{w c}\right.$ for mitochondrial DNA: $0.0347 /$ 0.0052; for acm4: $0.0051 / 0.0022$; for mc1r: $0.0029 /$ 0.0013; for $p d c: 0.0097 / 0.0043 ; P=0.001$; see Additional file 5). This allowed us to perform tests aiming at evaluating whether the genetic distance between northern and southern localities is consistent with the distance typically observed either between or within clades. Results from these analyses showed that mean pairwise distances between northern and southern localities are significantly different from within-clade differentiation, but not significantly different from between-clade distance (except locality 1), independently of the locus used for these comparisons (for more details see Additional file 5). Similar results were obtained when comparing northern localities to the sub-set of contiguous southern locations, although in this case this pattern is strong at mitochondrial but less evident at nuclear loci. These results support the hypothesis that populations of $P$. muralis from northern regions correspond to distinct evolutionary units from those occurring in southern peninsulas, and therefore that they have likely originated in situ rather than as a result of postglacial expansions of southern populations.

\section{Discussion}

The common wall lizard Podarcis muralis exhibited a complex phylogeographic pattern with multiple divergent mtDNA clades across its range. In total 23 allo- parapatric clades were identified, most of them with a restricted distribution in the Iberian, Italian, and Balkan peninsulas, as well as in Western and Eastern France, Slovenia and Austria, Central Balkans, and North-Western Anatolia. The detection of previously unidentified lineages was evidently due to the extended sampling scheme of this study as compared to earlier assessments, which were either focussed on a regional scale $[27,28]$, or did not sample all clades endemic to the Iberian, Balkan or Anatolian peninsulas [24]. Although the definition of clades is somewhat arbitrary, the lack of resolution of relationships between monophyletic haplogroups, their high divergence, their geographic coherence, and results from the SAMOVA analysis (Figure 1A,B; Additional file 4) indicate that a grouping into fewer lineages would not be practical and does not describe accurately the mitochondrial DNA diversity exhibited by $P$. muralis.

The observed phylogeographic structure of $P$. muralis does not match the current subspecific division of this species [22,23], as already reported by [27] and [28] for the 11 subspecies occurring in Italy. Regarding the subspecies found outside Italy, many divergent clades fall into P. m. brogniardii (clades $1-3,5$, and 6) and $P$. $m$. albanica (clades 12-14, and 18). Though a taxonomic revision is beyond the scope of this study, our results indicate that the current intraspecific taxonomy of $P$. muralis reflects local phenotypic varieties rather than distinct evolutionary units.

While mitochondrial data showed high variability and a clear geographic structure of genetic diversity, nuclear data showed both relatively low genetic variability and shallow divergence among populations. This finding is in agreement with allozyme data [49]; see also [26] from which low levels of polymorphism and genetic differentiation were identified (number of alleles per locus, $A=$ 1.07; proportion of polymorphic loci, $P=0.07$; observed heterozygosity, $H_{\mathrm{o}}=0.028$; genetic distance $D_{\mathrm{NEI}}=0.036$; average values from [49]) among 23 populations of $P$. muralis attributable to eight mitochondrial lineages described in our study (clades 1, 2, 3, 5, 9, 14, 22, and 23). Despite low differentiation in nuclear markers, $F_{\mathrm{ST}}$ values between mitochondrial clades are significant for all three nuclear markers and the mean between-clade pairwise distance is significantly different from that observed within clades, indicating that they are significant evolutionary lineages sensu [46]. Furthermore, even though overall nuclear data showed low genetic variation, a weak geographic association of nuclear haplotypes is apparent in sequence data. At the acm 4 and mc1r loci, besides a common widespread haplotype, some closely related derived haplotypes, relatively frequent, were found in the Balkans, Turkey, Slovenia, and Eastern France. This geographic association was more evident at the $p d c$ locus, where we observed two main haplotype groups: one including all haplotypes from Italy, and the other comprising haplotypes from the Balkans, Turkey, Slovenia, and Eastern France. Both haplogroups also occurred in Spain and Western France. Such shallow phylogeographic patterns at nuclear loci suggest that the divergence between mitochondrial clades has not been long enough for them to reach reciprocal monophyly at the nuclear level [50-52]. According to mitochondrial DNA TMRCA estimates, divergence among lineages is estimated to have occurred since the Early Pleistocene. Taking into account the slower evolutionary rates of nuclear genes, the genetic pattern observed at the mitochondrial and nuclear level is compatible with a scenario of Pleistocene divergence among lineages. Yet, the use of more variable markers such as microsatellites is needed for a full assessment of the nuclear pattern of variation within this species.

The finding of conspicuous genetic divergence among geographic clusters of populations has provided evidence for the existence of cryptic species within other Podarcis taxa including the P. erhardii [53], P. tiliguerta [31], and $P$. hispanica [54] species complexes. Given the extensive 
genetic structure observed in $P$. muralis and the lack of evidence for syntopy between mitochondrial lineages (except in four populations in Italy, see Figure 1), it might be suggested that some form of barrier to gene exchange has existed between distinct lineages. Nevertheless, we have no evidence that $P$. muralis constitutes a species complex. Pairwise uncorrected $p$-distances between clades ranges from 1.0 to $7.4 \%$ in $c y t b$ and from $0.9 \%$ to $4.7 \%$ in $n d 4$, which is a level of divergence typically found within (and not between) recognised species of the genus (e.g. $P$. vaucheri, [44]). Further, there is no evidence for high differentiation in nuclear markers which would be indicative of long-term independent evolutionary trajectories. While a low divergence level among genetic lineages is not necessarily a synonym of absence of reproductive isolation, the available evidence suggest that, contrary to other Podarcis forms, $P$. muralis is a single species and not a species complex.

This does not mean, however, that the genetic landscape of the species is uniform. On the contrary, genetic variation in $P$. muralis is structured in many distinct lineages across its range. The phylogeographic pattern observed, with many reciprocally monophyletic alloparapatric lineages having a Pleistocene divergence, suggests a scenario of long-term isolation in multiple ice-age refugia $[1,55]$. Therefore, the geographic distribution of these genetic lineages is likely to reflect the refugial structure of this species and indicate putative areas which allowed the long-term maintenance of its genetic diversity. Assessments of many widespread European species have recovered a classic pattern of higher genetic diversity and multiple genetic lineages within southern European peninsulas [2]. On one level the pattern of $P$. muralis is not an exception: more than three quarters of all lineages are endemic to the Iberian (2 and 3), the Italian (7-10, 19-23) and the Balkan peninsulas $(12-14,18)$. The simplest explanation for this phylogeographic pattern is one of a large number of refugia occurring not only across southern peninsulas, as pioneer works in phylogeography have demonstrated at a continental scale (e.g. [1]), but also within each peninsula, conforming to the "refugia within refugia" paradigm [56]. Such compartmentalization is particularly evident in Italy. Multiple, related lineages occur in South Italy, whereas other, unrelated lineages occur in central and northern regions. These latter lineages from central and northern regions were considered by [27] as belonging to a main lineage (clade " $1 \mathrm{~A}$ ") leading to the inference of a main refugial area north of Campania and Apulia. However, though this clade was not supported in any of their phylogenetic analyses $(\mathrm{BP} \leq 56, \mathrm{BPP}=0.54)$, in our analyses its constituent lineages are statistically well supported, unrelated, well differentiated one from the other, and parapatrically distributed. Thus, a scenario of multiple independent refugia in Central and Northern
Italy appears to fit the data better. A similar reasoning suggests the existence of multiple independent refugia in the southern Balkan Peninsula. On the other hand, the southern Italian Peninsula would have acted as an independent biogeographic compartment with four related lineages arising from distinct refugia within this main refugial area. The same situation is observed in the westernmost and easternmost areas of the species range - in the Iberian Peninsula and in Turkey. Here, two or three endemic related lineages, respectively, occupy geographically different regions that likely acted as distinct refugia within a main refugium. It is noteworthy that in Iberia, where the species currently has a discontinuous distribution, genetic discontinuities do not fully correspond to geographic isolates, suggesting recent fragmentation dynamics.

A scenario of survival in multiple refugia within a southern peninsula has been inferred for many species of the continental Europe fauna and detailed studies on amphibians and reptiles provide the best evidence (see [57] for a recent review). For example, there is evidence for multiple Iberian refugia in Salamandra salamandra [58], multiple Italian refugia in Triturus carnifex [59] and various Balkan refugia in Lacerta viridis [60]. To our knowledge, however, P. muralis is the first reported case of differentiation into multiple refugia within all Mediterranean peninsulas. In fact, within P. muralis, diversity and divergence levels are not strikingly different among these regions (Table 2), suggesting that all Mediterranean peninsulas significantly and simultaneously contributed to the long-term persistence of this species throughout the Pleistocene glaciations. Therefore, the case of $P$. muralis not only conforms to the scenario of "refugia within refugia" [56], but it also sets a new phylogeographic pattern of "refugia within all refugia".

According to the high number of lineages found in southern European peninsulas, the phylogeographic pattern of $P$. muralis fits the classical southern refugia model to some extent. However, while for many species of continental Europe these Mediterranean peninsulas were both glacial refugia and source areas for northward postglacial colonization $[2,4]$, in the case of $P$. muralis peninsular lineages are not found outside of these areas. This means that southern peninsulas acted as glacial refugia but not as sources for postglacial expansion. A possible explanation for such an unusual pattern is that northern areas outside Mediterranean peninsulas were already occupied by the species. In fact, various distinct lineages of $P$. muralis were found outside southern peninsulas, in the Pyrenees and France (clades 1 and 6), Northern Italy (clade 5), Slovenia and Austria (clade 11) and the Central Balkans (clade 4), reaching the highest latitudes of the species'range. Phylogenetic analyses and permution tests showed that these lineages are well 
differentiated and evolutionarily independent from southern lineages. The occurrence of two allopatric lineages in Western and Eastern France (clades 1 and 6), which are unrelated and considerably divergent from each other and relative to lineages occurring in Iberia (clade 2 and 3), and on the other side of the Alpine arch in North Italy (clade 5), provides evidence for a long-term persistence of $P$. muralis in these areas during Pleistocene glaciations, within separate refugia. Considering that the highest genetic diversity of these lineages is found along the southern portion of their range in SW and SE France respectively (data not shown), we can hypothesize that the refugia where these lineages differentiated were located in proximity of the Mediterranean coast and acted as source areas for post-glacial recolonization of Northern France and Germany. This hypothesis has been tested and validated by a recent study focused on $P$. muralis populations from France and Luxembourg [61], and it is further supported by palaeoclimatic and phylogeographic studies which indicate southern France as an area of prolonged ecological stability where climatic oscillations were attenuated [62] and where genetic signatures of refugia have been found among multiple species, including plants and animals (e.g. $[63,64])$. A similar reasoning applies to the allopatric mitochondrial lineages found in Northern Italy, Northern Adriatic, Eastern Slovenia and Austria, and Central Balkans (clades 5, 21, 11, and 4), which are allopatric and reciprocally monophyletic, thus suggesting long-term isolation in multiple ice-age refugia. The long-term persistence of temperate species in Northern Italy (including the Po Plain and the southern foothills of the Alps) and in the Northern Adriatic has been inferred for many amphibians and reptiles in recent phylogeographic studies based on the occurrence of divergent lineages endemic to these areas (e.g., Hyla intermedia, Pelobates fuscus, Pelophylax lessonae, Triturus carnifex, Podarcis sicula; see $[59,65])$. Likewise, in the area spanning from the Eastern Alps to the South-Western Pannonian region, palaeobotanical, paleoclimatic, and genetic data indicate that temperate species such as the tree Fagus sylvatica and the butterfly Erebia medusa survived in isolated refugia during glacial periods $[20,21,66,67]$. Finally, a refugial area in the central Balkans and southwestern Carpathians has already been suggested for many species showing high genetic diversity and distinct lineages in this area where also broad-leaved trees survived glacial periods (e.g. [16,66-68]).

Altogether these phylogeographic, palaeobotanical and palaeoclimatic studies provide evidence for the long-term persistence of temperate organisms outside the traditional refugia in southern peninsulas, and underline the prominent contribution of these northern refugia to the present-day genetic pools of many temperate species.

\section{Conclusions}

In recent decades, the phylogeography of the Western Palaearctic has been mainly centered around the southern refugia model, which sets a sharp dichotomy between Mediterranean peninsulas and Northern Europe, the former being areas of long-term persistence of temperate species and sources for the postglacial assembly of northern biotas. Our data do not strictly conform to this model: a pattern of northern purity was not detected, whereas several evolutionary units endemic to northern regions were identifed. Overall, the occurrence of many reciprocally monophyletic lineages within $P$. muralis suggests a history of long-term persistence in multiple glacial refugia across its distribution, providing a paradigm of iceage survival of temperate species in Mediterranean and extra-Mediterranean refugia [12]. Contrary to previous hypotheses $[25,27,28]$ this species did not occupy most of its present range only recently, either from the Italian Peninsula or from any other southern peninsular refugium.

In the last two decades mounting evidence for glacial survival in northern refugia through the Pleistocene has been found among various organisms representing different biogeographical groups ([12] for a review). These studies suggest that the assembly of northern European biota was not simply the outcome of long-distance postglacial re-colonization from southern peninsulas $[6,7]$. Rather, extra-Mediterranean refugia allowed the longterm persistence and differentiation of distinct genetic lineages of many organisms in the Western Palaearctic and acted as source areas for post-glacial colonization of Central and Northern Europe [12]. These biogeographic insights in the Western Palaearctic are paralleled by phylogeographic and palaeobotanical evidence for survival during ice ages of populations of temperate organisms in northern refugia located in the Eastern Palaearctic [69], as well as in the Nearctic region [70-72] providing directions for future research in the Holarctic ecozone concerning the role of northern regions as areas of long-term persistence of temperate biotas.

Understanding the relative contribution of Mediterranean and extra-Mediterranean refugia to the current patterns of genetic diversity may allow us to significantly improve our current knowledge regarding glacial refugia dynamics, the extent and the routes of dispersal between subregions and their consequences in terms of evolutionary and demographic processes [9-12,73]. Moreover, our understanding of northern refugial biodiversity has deep consequences for conservation. The survival of temperate biota in northern refugia across a matrix of unsuitable glacial landscapes challenges the view that organisms must have gone extinct in northern regions during glaciations, and suggests that, in many cases, postglacial colonisation routes - and thus migration capacity - tracking the expansion of suitable habitats have been much smaller 
than previously thought $[9-12,68,74]$. Our appraisal of past species resilience, and of their ability to track suitable habitats in response to past climatic shifts, is crucial to better forecast their future performance under global climate change scenarios [10,73,75-77], and thus essential for more informed decisions aimed at long-term conservation of biodiversity.

\section{Additional files}

Additional file 1: Details on Sequences from GenBank used in the study. Accession numbers, localities, and references for the 103 cytb sequences obtained from GenBank used in the phylogenetic analyses.

Additional file 2: Primers used for amplification and sequencing.

Primers sequences and reference for each gene are reported.

Additional file 3: Times to the most recent common ancestor estimates. Times to the most recent common ancestor of supported mitochondrial DNA clades within P. muralis (in million years) estimated in BEAST. Values in parenthesis refer to the lower and higher limits of the 95\% highest posterior density interval.

Additional file 4: SAMOVA (Spatial Analysis of Molecular Variance) design and results. A: Geographic location of mitochondrial clades estimated as the centroid between member localities (see also Figure 1). B: Localities and sequences included in each mitochondrial clade as defined by previous phylogenetic analyses. C: SAMOVA results showing relative fixation indices $F_{C G}$ and $F_{S C}(P<0.001)$ for pre-defined value of $K$ from 2 to 10 (after $K=10$ structures are not informative as one population at a time is removed from the groups structure).

Additional file 5: Statistical comparison between the hypotheses of southern vs. in situ origin of northern localities.

\section{Competing interests}

The authors declare that they have no competing interests.

\section{Authors' contributions}

All authors conceived and designed the study, participated in data acquisition, and critically revised and approved the final version of the manuscript; DS, CP analysed the data; DS, CP, DJH drafted the manuscript; $\mathrm{CP}, \mathrm{DJH}, \mathrm{MAC}$ provided funding

\section{Acknowledgements}

We thank Susana Lopes for assistance in laboratory work and Marco Bologna, Pierluigi Bombi, Jelka Crnobrnja-Isailović, Angelica Crottini, Marko Lazić, Guillem Pérez-Lanuza and Anamarija Žagar for field sampling. Petros Lymberakis kindly provided tissue samples from specimens deposited in the Natural History Museum of Crete. Lizards were captured and handled under permits from the Italian Ministry of Environment (DPN/2D/2003/2267) and the environmental authorities of Spain, Slovenia, Serbia, and Turkey. This work was partially supported by FEDER through the COMPETE program; the Project "Genomics and Evolutionary Biology" cofinanced by North Portugal Regional Operational Programme 2007/2013 (ON.2 - O Novo Norte), under the National Strategic Reference Framework (NSRF), through the European Regional Development Fund (ERDF); Portuguese national funds through the FCT (Fundação para a Ciência e a Tecnologia, Portugal) PTDC/BIA-BEC/ 102179/2008 and PTDC/BIA-BEC/101256/2008 research projects, integrated action Portugal-Serbia; and the Gulbenkian Foundation. DS, AK, and CP are supported by FCT post-doctoral fellowships under the Programa Operacional Potencial Humano - Quadro de Referência Estratégico Nacional funds from the European Social Fund and Portuguese Ministério da Educação e Ciência (DS: SFRH/BPD/66592/2009, AK: SFRH/BPD/68493/2010, and CP: SFRH/BPD/ 28869/2006)

Received: 7 January 2013 Accepted: 8 July 2013

Published: 11 July 2013
References

1. Hewitt GM: The genetic legacy of the Quaternary ice ages. Nature 2000, 405:907-913.

2. Hewitt GM: The structure of biodiversity - insights from molecular phylogeography. Front Zool 2004, 1:4

3. Widmer A, Lexer C: Glacial refugia: sanctuaries for allelic richness, but not for gene diversity. Trends Ecol Evol 2001, 16:267-269.

4. Schmitt T: Molecular Biogeography of Europe: pleistocene cycles and postglacial trends. Front Zool 2007, 4:11

5. Hewitt GM: Some genetic consequences of ice ages and their role in divergence and speciation. Biol J Linn Soc Lond 1996, 58:247-276.

6. Hewitt GM: Post-glacial re-colonization of European biota. Biol J Linn SoC Lond 1999, 68:87-112.

7. Taberlet P, Fumagalli L, Wust-Saucy AG, Cosson JF: Comparative phylogeography and postglacial colonization routes in Europe. Mol Ecol 1998, 7:453-464

8. Habel JC, Schmitt T, Müller P: The fourth paradigm pattern of post-glacial range expansion of European terrestrial species: the phylogeography of the Marbled White butterfly (Satyrinae, Lepidoptera). J Biogeogr 2005, 32:1489-1497

9. Stewart JR, Lister AM: Cryptic northern refugia and the origins of the modern biota. Trends Ecol Evol 2001, 16:608-613.

10. Provan J, Bennett KD: Phylogeographic insights into cryptic glacial refugia. Trends Ecol Evol 2008, 23:564-571.

11. Stewart JR, Lister AM, Barnes I, Dalén L: Refugia revisited: individualistic responses of species in space and time. Proc R Soc Lond B Biol Sci 2010, 277:661-671.

12. Schmitt T, Varga $Z$ : Extra-Mediterranean refugia: the rule and not the exception? Front Zool 2012, 9:22.

13. Deffontaine V, Libois R, Kotlík P, Sommer R, Nieberding C, Paradis E, Searle $J B$, Michaux JR: Beyond the Mediterranean peninsulas: evidence of Central European glacial refugia for a temperate forest mammal species, the bank vole (Clethrionomys glareolus). Mol Ecol 2005, 14:1727-1739.

14. Rowe G, Harris DJ, Beebee TJC: Lusitania revisited: a phylogeographic analysis of the natterjack toad Bufo calamita across its entire biogeographical range. Mol Phylogenet Evol 2006, 39:335-346.

15. Joger U, Fritz U, Guicking D, Kalyabina-Hauf S, Nagy ZT, Wink M: Phylogeography of western Palaearctic reptiles - Spatial and temporal speciation patterns. Zool Anz 2007, 246:293-313.

16. Kotlík P, Deffontaine V, Mascheretti S, Zima J, Michaux JR, Searle JB: A northern glacial refugium for bank voles (Clethrionomys glareolus). Proc Natl Acad Sci USA 2006, 103:14860-14864.

17. Varga Z: Extra-Mediterranean refugia, post-glacial vegetation history and area dynamics in Eastern Central Europe. In Relict Species: Phylogeography and Conservation Biology. Edited by Habel JC, Assmann T. Heidelberg: Springer; 2010:57-87.

18. Saarma U, Ho SY, Pybus OG, Kaljuste M, Tumanov IL, Kojola I, Vorobiev AA, Markov NI, Saveljev AP, Valdmann H, Lyapunova EA, Abramov AV, Männil P Korsten M, Vulla E, Pazetnov SV, Pazetnov VS, Putchkovskiy SV, Rõkov AM: Mitogenetic structure of brown bears (Ursus arctos L.) in northeastern Europe and a new time frame for the formation of European brown bear lineages. Mol Ecol 2007, 16:401-13.

19. Valdiosera CE, Garcia N, Anderlung C, Dalen L, Cregut-Bonnoure E, Kahlke RD, Stiller M, Brandström M, Thomas MG, Arsuaga J-L, Götherström A, Barnes I: Staying out in the cold: glacial refugia and mitochondrial DNA phylogeography in ancient European brown bears. Mol Ecol 2007, 16:5140-5148

20. Magri D, Vendramin GG, Comps B, Dupanloup I, Geburek T, Gömöry D, Latałowa M, Litt T, Paule L, Roure JM, Tantau I, van der Knaap WO, Petit RJ, De Beaulieu JL: A new scenario for the Quaternary history of European beech populations: palaeobotanical evidence and genetic consequences. New Phytol 2006, 171:199-221.

21. Magri D: Patterns of post-glacial spread and the extent of glacial refugia of European beech (Fagus sylvatica). J Biogeogr 2008, 35:450-463.

22. Gruschwitz M, Böhme W: Podarcis muralis (Laurenti, 1768) Mauereidechse. In Handbuch der Reptilien und Amphibien Europas, Band 2/II, Echsen (Sauria) III (Lacertidae III: Podarcis). Edited by Böhme W. Wiesbaden: Aula-Verlag; 1986:155--208.

23. Biaggini M, Bombi P, Capula M, Corti C: Podarcis muralis (Laurenti, 1768). In Fauna d'Italia, vol.5, Reptilia. Edited by Corti C, Capula M, Luiselli L, Razzetti E, Sindaco R. Bologna: Calderini; 2011:391-401. 
24. Schulte $U$, Veith $M$, Hochkirch A: Rapid genetic assimilation of native wall lizard populations (Podarcis muralis) through extensive hybridization with introduced lineages. Mol Ecol 2012, 17:4313-4326.

25. Harris DJ, Arnold EN: Relationships of Wall Lizards, Podarcis (Reptilia: Lacertidae) based on Mitochondrial DNA sequences. Copeia 1999, 3:749-754

26. Capula M: High genetic variability in insular populations of the lacertid lizard, Podarcis muralis. Biochem Syst Ecol 1997, 25:411-417.

27. Giovannotti M, Nisi-Cerioni $P$, Caputo V: Mitochondrial DNA sequence analysis reveals multiple Pleistocene glacial refugia for Podarcis muralis (Laurenti, 1768) in the Italian Peninsula. Ital J Zool 2010, 77:277-288.

28. Bellati A, Pellitteri-Rosa D, Sacchi R, Nistri A, Galimberti A, Casiraghi M, Fasola M, Galeotti P: Molecular survey of morphological subspecies reveals new mitochondrial lineages in Podarcis muralis (Squamata: Lacertidae) from the Tuscan Archipelago (Italy). J Zoolog Syst Evol Res 2011, 49:240-250.

29. Salvi D, Harris DJ, Bombi P, Carretero MA, Bologna MA: Mitochondrial phylogeography of the Bedriaga's rock lizard, Archaeolacerta bedriagae (Reptilia: Lacertidae) endemic to Corsica and Sardinia. Mol Phylogenet Evol 2010, 56:690-697.

30. Barata M, Carranza S, Harris DJ: Extreme genetic diversity in the lizard Atlantolacerta andreanskyi (Werner, 1929): a montane cryptic species complex. BMC Evol Biol 2012, 12:167.

31. Harris DJ, Pinho C, Carretero MA, Corti C, Böhme W: Determination of genetic diversity within the insular lizard Podarcis tiliguerta using mtDNA sequence data, with a reassessment of the phylogeny of Podarcis. Amphibia-Reptilia 2005, 26:401-407.

32. Pyron RA, Burbrink FT, Wiens JJ: A phylogeny and revised classification of Squamata, including 4161 species of lizards and snakes. BMC Evol Biol 2013, 13:93.

33. Sambrook J, Fritsch EF, Maniatis T: Molecular Cloning: A Laboratory Manual. 2nd edition. New York: Cold Spring Harbor Press; 1989.

34. Harris DJ: Reassessment of comparative genetic distance in reptiles from the mitochondrial cytochrome $b$ gene. Herpetol J 2002, 12:85-86.

35. Stephens M, Smith NJ, Donnelly P: A new statistical method for haplotype reconstruction from population data. Am J Hum Genet 2001, 68:978-989.

36. Bruen T, Phillipe $H$, Bryant D: A quick and robust statis-tical test to detect the presence of recombination. Genetics 2006, 172:2665-2681.

37. Huson DH, Bryant D: Application of phylogenetic networks in evolutionary studies. Mol Biol Evol 2006, 23:254-267.

38. Librado P, Rozas J: DnaSP v5: A software for comprehensive analysis of DNA polymorphism data. Bioinformatics 2009, 25:1451-1452.

39. Tamura K, Peterson D, Peterson N, Stecher G, Nei M, Kumar S: MEGA5: molecular evolutionary genetics analysis using maximum likelihood, evolutionary distance, and maximum parsimony methods. Mol Biol Evol 2011, 28:2731-2739.

40. Excoffier L, Laval G, Schneider S: Arlequin ver. 3.0: an integrated software package for population genetics data analysis. Evol Bioinformatics Online 2005, 1:47-50.

41. Jobb G: TREEFINDER version of October 2008. Germany: Munich; 2008 Distributed by the author at www.treefinder.de.

42. Drummond AJ, Suchard MA, Xie D, Rambaut A: Bayesian phylogenetics with BEAUti and the BEAST 1.7. Mol Biol Evol 2012, 29:1969-1973.

43. Drummond A, Ho S, Phillips M, Rambaut A: Relaxed phylogenetics and dating with confidence. PLOS Biol 2006, 4:699.

44. Pinho C, Harris DJ, Ferrand N: Contrasting patterns of population subdivision and historical demography in three western Mediterranean lizard species inferred from mitochondrial DNA variation. Mol Ecol 2007 16:1191-205.

45. Fouquet A, Noonan B, Rodrigues MT, Pech N, Gilles A, Gemmell NJ: Multiple quaternary refugia in the Eastern Guiana Shield revealed by comparative phylogeography of 12 frog species. Syst Bio/ 2012, 61(3):461-489.

46. Moritz C: Defining "Evolutionary Significant Units" for conservation. Trends Ecol Evol 1994, 9(10):373-375.

47. Dupanloup I, Schneider S, Excoffier L: A simulated annealing approach to define the genetic structure of populations. Mol Ecol 2002, 11:2571-2581.

48. Bandelt HJ, Forster $P$, Rohl A: Median-joining networks for inferring intraspecific phylogenies. Mol Biol Evol 1999, 16:37-45.

49. Capula M, Corti C: Genetic variability in mainland and insular populations of Podarcis muralis (Reptilia: Lacertidae). Bonn Zool Bull 2010, 57:189-196

50. Moore WS: Inferring phylogenies from mtDNA variation: mitochondrialgen trees versus nuclear-gen trees. Evolution 1995, 49:718-726.
51. Palumbi SR, Ciprinao F, Hare MP: Predicting nuclear gene coalescence from mitochondrial data: the three time-rule. Evolution 2001, 55:859-868.

52. Hudson RR, Turelli M: Stochasticity overrules the 'three-time rule': genetic drift, genetic draft and coalescence times for nuclear loci vs. mtDNA. Evolution 2003, 57:182-190

53. Poulakakis N, Lymberakis P, Antoniou A, Chalkia D, Zouros E, Mylonas M Valakos E: Molecular phylogeny and biogeography of the wall-lizard Podarcis erhardii (Squamata: Lacertidae). Mol Phylogenet Evol 2003, 28:38-46.

54. Kaliontzopoulou A, Pinho C, Harris DJ, Carretero MA: When cryptic diversity blurs the picture: a cautionary tale from Iberian and North African Podarcis wall lizards. Biol J Linn Soc Lond 2011, 103:779-800.

55. Avise JC: Phylogeography: the history and formation of the species. Harvard: University Press; 2000.

56. Gómez A, Lunt DH: Refugia within refugia: patterns of phylogeographic concordance in the Iberian Peninsula. In Phylogeography in southern European refugia: evolutionary perspectives on the origins and conservation of European biodiversity. Edited by Weiss S, Ferrand N. Dordrecht: Springer Verlag; 2007:155-188

57. Hewitt GM: Mediterranean Peninsulas - the evolution of hotspots. In Biodiversity hotspots. Edited by Zachos FE, Habel JC. Heidelberg: Springer; 2011:123-147.

58. García-París M, Alcobendas M, Buckley D, Wake DB: Dispersal of viviparity across contact zones in Iberian populations of fire salamanders (Salamandra) inferred from discordance of genetic and morphological traits. Evolution 2003, 57:129-143.

59. Canestrelli D, Salvi D, Maura M, Bologna MA, Nascetti G: One Species, three Pleistocene evolutionary histories: phylogeography of the Italian crested newt. Triturus carnifex. PLOS ONE 2012, 7(7):e41754.

60. Böhme MU, Fritz U, Kotenko T, Džukić G, Ljubisavljević K, Tzankov N, Berendonk TU: Phylogeography and cryptic variation within the Lacerta viridis complex. Zool Scr 2007, 36:119-131.

61. Gassert F, Schulte U, Husemann M, Ulrich W, Rödder D, Hochkirch A, Engel $E$, Meyer J, Habel JC: From southern refugia to the northern range margin: genetic population structure of the common wall lizard, Podarcis muralis. J Biogeogr 2013. in press, DOI: 10.1111/jbi.12109.

62. Elenga $\mathrm{H}$, Peyron O, BonneWlle R, Jolly D, Cheddadi R, Guiot J, Andrieu V, Bottema S, Buchet G, De Beaulieu JL, Hamilton AC, Maley J, Marchant R, Perez-Obiol R, Reille M, Riollet G, Scott L, Straka H, Taylor D, Van Campo E, Vincens A, Laarif F, Jon-son H: Pollen-based biome reconstruction for southern Europe and Africa18,000 yr BP. J Biogeogr 2000, 27:621-634.

63. Vogel JC, Rumsey FJ, Schneller JJ, Barrett JA, Gibby M: Where are the glacial refugia in Europe? Evidence from pteridophytes. Biol J Linn Soc Lond 1999, 66:23-37.

64. Ursenbacher S, Conelli A, Golay P, Monney J-C, Zuffi MAL, Thiery G, Durand T, Fumagalli L: Phylogeography of the asp viper (Vipera aspis) inferred from mitochondrial DNA sequence data: evidence for multiple Mediterranean refugial areas. Mol Phylogenet Evol 2006, 38:546-552.

65. Litvinchuk SN, Crottini A, Federici S, De Pous P, Donaire D, Andreone F, Kalezić ML, Džukić G, Lada GA, Borkin LJ, Rosanov JM: Phylogeographic patterns of genetic diversity in the common spadefoot toad, Pelobates fuscus (Anura: Pelobatidae), reveals evolutionary history, postglacial range expansion and secondary contact. Org Divers Evol 2013. in press, DOl 10.1007/s13127-013-0127-5.

66. Willis KJ, Van Andel T: Trees or no trees? The environments of central and eastern Europe during the last glaciation. Quat Sci Rev 2004, 23:2369-2387.

67. Hammouti N, Schmitt T, Seitz A, Kosuch J, Veith M: Combining mitochondrial and nuclear evidences: a refined evolutionary history of Erebia medusa (Lepidoptera: Nymphalidae: Satyrinae) in Central Europe based on the CO1 gene. J Zool Syst Evol Res 2010, 48:115-125.

68. Ursenbacher S, Schweiger S, Tomovic L, Crnobrnja-Isailovic J, Fumagalli L, Mayer W: Molecular phylogeography of the nose-horned viper (Vipera ammodytes, Linnaeus (1758)): evidence for high genetic diversity and multiple refugia in the Balkan peninsula. Mol Phylogenet Evol 2008 46:1116-1128.

69. Korsten M, Ho SY, Davison J, Pähn B, Vulla E, Roht M, Tumanov IL, Kojola I, Andersone-Lilley Z, Ozolins J, Pilot M, Mertzanis Y, Giannakopoulos A, Vorobiev AA, Markov NI, Saveljev AP, Lyapunova EA, Abramov AV, Männil P, Valdmann H, Pazetnov SV, Pazetnov VS, Rõkov AM, Saarma U: Sudden expansion of a single brown bear maternal lineage across northern continental Eurasia after the last ice age: a general demographic model for mammals? Mol Ecol 2009, 18:1963-1979. 
70. Jackson ST, Webb RS, Anderson KH, Overpeck JT, Webb T III, Williams JW, Hansen BCS: Vegetation and environment in eastern North America during the last glacial maximum. Quat Sci Rev 2000, 19:489-508.

71. Rowe KC, Heske EJ, Brown PW, Paige KN: Surviving the ice: Northern refugia and postglacial colonization. Proc Natl Acad Sci USA 2004, 101:10355-10359.

72. Pruett $\mathrm{CL}$, Winker $\mathrm{K}$ : Evidence for cryptic northern refugia among highand temperate-latitude species in Beringia. Clim Change 2008, 86:23-27.

73. Keppel G, Van Niel KP, Wardell-Johnson GW, Yates CJ, Byrne M, Byrne M, Mucina L, Schut AGT, Hopper SD, Franklin SE: Refugia: identifying and understanding safe havens for biodiversity under climate change. Global Ecol Biogeogr 2012, 21:393-404.

74. Anderson LL, Hu FS, Nelson DM, Petit RJ, Paige KN: Ice-age endurance: DNA evidence of a white spruce refugium in Alaska. Proc Natl Acad Sci USA 2006, 103:12447-12450.

75. Lawing AM, Polly PD: Pleistocene climate, phylogeny, and climate envelope models: an integrative approach to better understand species' response to climate change. PLoS One 2011, 16(12):e28554.

76. Willis KJ, Bhagwat SA: Questions of importance to the conservation of global biological diversity: answers from the past. Clim. Past Discuss 2010, 6:1139-1162.

77. Willis K, Bennett KD, Froyd C, Figueroa-Rangel B: How can a knowledge of the past help to conserve the future? Biodiversity conservation strategies and the relevance of long-term ecological studies. Phil. Trans. R. Soc. B 2007, 362:175-186.

doi:10.1186/1471-2148-13-147

Cite this article as: Salvi et al:: Persistence across Pleistocene ice ages in Mediterranean and extra-Mediterranean refugia: phylogeographic insights from the common wall lizard. BMC Evolutionary Biology 2013 13:147

\section{Submit your next manuscript to BioMed Central and take full advantage of:}

- Convenient online submission

- Thorough peer review

- No space constraints or color figure charges

- Immediate publication on acceptance

- Inclusion in PubMed, CAS, Scopus and Google Scholar

- Research which is freely available for redistribution 